\title{
NANO-SPONGE NOVEL DRUG DELIVERY SYSTEM AS CARRIER OF ANTI-HYPERTENSIVE DRUG
}

\author{
MONA IBRAHIM EL-ASSAL ${ }^{*}$ \\ ${ }^{* 1}$ Department of Pharmaceutics and Pharmaceutical Technology, Faculty of Pharmaceutical Sciences and Pharmaceutical Industries, \\ Future University in Egypt, 11835, Cairo, Egypt \\ Email: mona.ibrahim@fue.edu.eg
}

Received: 07 Jul 2019, Revised and Accepted: 13 Sep 2019

\section{ABSTRACT}

Objective: The study was designed to prepare Nano-sponge formulation loaded with nifedipine. Studying parameters which affecting the formulas in addition to pharmacokinetics and toxicity tests.

Methods: Nine Nano-sponge formulations were prepared by the solvent evaporation technique. Different ratios of polymer ethylcellulose, COpolymers $\beta$-cyclodextrin and hydroxypropyl $\beta$-cyclodextrin in addition to solubilizing agent polyvinyl alcohol were used. Thermal analysis, X-ray powder diffraction (XRPD), shape and surface morphology, particle size, \%production yield, \%porosity, \% swelling, and \% drug entrapment efficiency of Nano-sponge were examined. Release kinetic also studied beside comparison of pharmacokinetic parameters of the optimum choice formula and marketed one in addition to Toxicological consideration.

Results: Particle size in the range of $119.1 \mathrm{~nm}$ to $529 \mathrm{~nm}$ which were increased due to the increase in the concentration of polymer to the drug. Nano-sponge revealed porous, spherical nature. Increased in the drug/polymer molar ratios $(1: 1$ to 1:3) may increase their \% production yield ranged from $62.1 \%$ to $92.4 \%$. The drug content of different formulations was in the range of $77.9 \%$ to $94.7 \%$, and entrapment efficiency was in the range of $82.72 \%$ to $96.63 \%$. Drug released in controlled sustained pattern and followed Higuchi, s diffusion mechanism. Pharmacokinetic parameters of optimized formula showed significant higher maximum plasma drug concentration, area under plasma concentration-time curve, volume of distribution and mean residence time. Nano-sponge loaded drug proved biological safety at low concentrations.

Conclusion: Nano-sponge drug delivery system has showed small Nano size, porous with controlled drug release and significant-high plasma drug concentration that improved solubility, drug bioavailability and proved safety.

Keywords: Cyclodextrins, Polymeric drug delivery system, Controlled release, Nanotechnology, Preclinical pharmacokinetics, Cytotoxicity

(C) 2019 The Authors. Published by Innovare Academic Sciences Pvt Ltd. This is an open-access article under the CC BY license (http://creativecommons.org/licenses/by/4.0/) DOI: http://dx.doi.org/10.22159/ijpps.2019v11i10.34812

\section{INTRODUCTION}

Nano-sponge is novel class of hyper-cross linked polymer-based colloidal structures consisting of solid nanoparticles with colloidal sizes and Nanosized cavities. They enhance stability, reduce side effects and modify drug release. The outer surface is typically porous, allowing sustain release of drug [1]. Nano-sponge is small spherical particles with large porous surface. Nano-sponge can significantly reduce the irritation of drugs without reducing their efficacy. The size of the Nano-sponge ranges in diameter from 250 $\mathrm{nm}$ to $1 \mu \mathrm{m}$ [2]. These particles are capable of carrying both lipophilic and hydrophilic substances and of improving the solubility of poor water-soluble molecules [3]. Nano-sponge is encapsulating type of nanoparticles which encapsulates the drug molecules within its core [4]. They can be used for targeting drugs to specific sites, to release the drug in a controlled and predictable manner [5]. It is possible to control the size of Nano-sponge by varying the portion of cross-linkers and polymers. This technology is five times more effective at delivering drugs for breast cancer than conventional methods [6]. Nano-sponge are non-irritating, non-mutagenic, no allergenic and non-toxic [7]. They are solid in nature and can be formulated as oral, parenteral, topical or inhalational dosage forms $[8,9]$. Topical Nano-sponge can be more patient compliant and provide sufficient patient benefits by reducing repeated doses and side effects [10]. Nifedipine is chemically known as dimethyl-1, 4dihydro-2, 6-dimethyl-4-(2-nitrophenyl) pyridine-3, 5 dicarboxylate (fig. 1A). It is pharmacologically a selective L-type calcium channel antagonist (Martindale the Extra Pharmacopoeia, 2002). It causes coronary vasodilation and increases coronary blood flow. It reduces the total peripheral vascular resistance, for which it is widely used in the treatment of hypertension, angina pectoris, various other cardiovascular disorders and Reynaud's phenomenon [11]. Although calcium channels antagonists are still favored as primary treatment for older black patients and sub-lingual nifedipine has previously been used in hypertensive emergencies, it has a very low bioavailability, and it is photosensitive and thermally unstable. This compound, when exposed to daylight and certain wavelengths of artificial light readily converts to a nitrophenyl pyridine derivative (NFPD) (fig. 1B) [12]. Nifedipine is a commonly prescribed active ingredient for CVD. It is a highly non-polar compound, absorbed completely from the gastrointestinal tract, predominately from the Jejunum, but has a very low bioavailability mainly due to presystemic metabolism. Following absorption, nifedipine is further metabolized in the small intestine and liver to more polar compounds which are primarily eliminated by the kidney [13]. Nifedipine is a photolabile compound, undergoing oxidative biotransformation in human body into pharmacologically inactive metabolites [14]. In the present study nifedipine was formulated as a Nano-sponge system helps to retain the drug for longer period and to increase the solubility and bioavailability with decrease side effects.

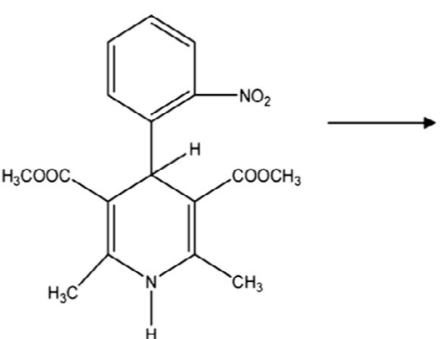

(A)<smiles></smiles>

(B)
Fig. 1: Chemical structures of (A) Nifedipine (B) Nitro phenyl pyridine 


\section{MATERIALS AND METHODS}

\section{Materials}

Nifedipine pure drug was kindly gifted from E. I. P. I. CO. Egyptian international Pharmaceutical Industries CO., Egypt. Polyvinyl alcohol (PVA; M. Wt. 22000 Da), dichloromethane and Ortho-phosphoric acid (Riedel-de Haën, Germany), were purchased from El-Shark al-Awsat Chemical Trading Company, Egypt. Ethylcellulose, $\beta$-cyclodextrin and hydroxypropyl $\beta$-cyclodextrin were purchased from Sigma-Aldrich, chemical Trade Company, Egypt, Hexane HPLC grade, Acetonitrile HPLC grade and Dichloromethane HPLC grade were purchased from (Merck, Darmstadt, Germany), water used all over the study was double distilled and of high purity. All other chemicals used are analytical grade and were used without further purification.

\section{Methods}

Preparation of nano-sponge by emulsion-solvent evaporation method

Nano-sponge were prepared by emulsion solvent evaporation method using different proportions of ethyl cellulose as rate retarding polymer, co-polymers $\beta$-cyclodextrin and HP $\beta$ cyclodextrin and solubilizing agent polyvinyl alcohol. Disperse phase consisting of nifedipine $(20 \mathrm{mg})$ and requisite quantity of ethyl cellulose dissolved in $10 \mathrm{ml}$ solvent (dichloromethane) was slowly added dropwise to a definite amount of PVA in $40 \mathrm{ml}$ of aqueous continuous phase. PVA was alternated with each of $\beta$-cyclodextrin and HP $\beta$-cyclodextrin. The reaction mixture was stirred at 1000 $\mathrm{r} / \mathrm{min}$ for two $\mathrm{h}$ on a magnetic stirrer at $45{ }^{\circ} \mathrm{C}$. The Nano-sponge formed were collected by centrifugation at $3000 \mathrm{r} / \mathrm{min}$ for $5 \mathrm{~min}$ through Nano-separation tube (Pall-USA), washed and were dried in air at room temperature. The dried Nano-sponge was stored in vacuum desiccator to ensure the removal of residual solvent, fig. 2 .

\section{Formula optimization}

Nine different formulations were prepared with different ratios between ethylcellulose polymer and co-polymers $\beta$-cyclodextrin, HP $\beta$-cyclodextrin and solubilizing agent polyvinyl alcohol as shown in table 1. Each of drug concentration, volume of solvents, stirring speed and time also temperature were constant.

\section{Evaluation parameters}

\section{Drug content uniformity}

The prepared Nano-sponge formulations of nifedipine were tested for their drug content. Powder of each dried formula was taken and triturated properly. Then a quantity of powder equivalent to $20 \mathrm{mg}$ of drug was mixed with $20 \mathrm{ml}$ phosphate buffer $\mathrm{pH} 6.8$ and shaken properly in incubator shaker (IKA KS $4000 \boldsymbol{i}$ Germany), at (160 $\mathrm{r} / \mathrm{min}$ ) for $24 \mathrm{~h}$ at $37^{\circ} \mathrm{C}$. Then it was filtered through Whatman filter paper size 41 , diluted to analyze for nifedipine content at $\lambda$ max 235 $\mathrm{nm}$ using U. V Spectrophotometer (Shimadzu-UV/800, Japan).

Table 1: Formulation table of nifedipine loaded nano-sponge

\begin{tabular}{|c|c|c|c|c|c|c|c|c|c|c|}
\hline S. No. & Ingredients & F1 & F2 & F3 & F4 & F5 & F6 & F7 & F8 & F9 \\
\hline 1. & Nifedipine (mg) & 20 & 20 & 20 & 20 & 20 & 20 & 20 & 20 & 20 \\
\hline 2. & Ethyl cellulose (mg) & 10 & 20 & 30 & 10 & 20 & 30 & 10 & 20 & 30 \\
\hline 3. & Polyvinyl alcohol (mg) & 10 & 10 & 10 & --- & --- & --- & --- & --- & -- \\
\hline 4. & $\beta$-cyclodextrin (mg) & --- & --- & --- & 10 & 10 & 10 & --- & --- & --- \\
\hline 5. & HP $\beta$ cyclodextrin (mg) & -- & --- & --- & --- & --- & --- & 10 & 10 & 10 \\
\hline 6. & Dichloromethane (ml) & 10 & 10 & 10 & 10 & 10 & 10 & 10 & 10 & 10 \\
\hline 7. & Distilled Water (ml) & 40 & 40 & 40 & 40 & 40 & 40 & 40 & 40 & 40 \\
\hline
\end{tabular}

\section{Differential scanning calorimetric (DSC)}

Thermal analysis was used in order to elucidate any interactions between drug, investigated polymer and Co-polymer. DSC was carried out using Shimadzu, DSC 60 thermal analyzer (Japan) with a liquid nitrogen cooling accessory. The analysis was performed under a purge of dry nitrogen gas $\left(40 \mathrm{~mL} / \mathrm{min}^{-1}\right)$. A sample of $2-5 \mathrm{mg}$ was placed in an aluminum crucible cell and was firmly crimped with the lid to provide an adequate seal. The samples were heated from ambient temperature to $400{ }^{\circ} \mathrm{Cat}$ a preprogrammed heating rate of $10{ }^{\circ} \mathrm{C} / \mathrm{min}^{-1}$. All samples either individual, physical mixture or loaded Nano-sponge were analyzed in the same manner.

\section{Fourier transform infra-red (FTIR) spectroscopy}

FTIR was used to study the molecular interaction between formulation components. The infrared spectrum of drug-loaded Nano-sponge sample was studied. FTIR spectra of ethylcellulose, $\beta$-cyclodextrin, pure drug, physical mixture and Nano-sponge were recorded by using an FT-IR spectrophotometer (Nexus 670, Nicolet, USA) in the region of $400-4000 \mathrm{~cm}^{-1}$ with spectra resolution of $4 \mathrm{~cm}^{-1}$.

\section{$\mathrm{X}$-ray powder diffraction}

X-ray diffracted peaks were obtained using the Philips X, Pert on powder diffraction coordination (Philips Analytical, the Netherlands) set with a directly set up goniometer in the BraggBrentano focusing geometry. The X-ray generator was operated at $40 \mathrm{KV}$ and $40 \mathrm{~mA}$, using the $\mathrm{CuK \alpha}$ line at $1.54060 \mathrm{~A}$ as the radiation source. The samples were ground using a mortar and pestle. The crushed specimen was filled and arranged in a specimen holder made of aluminum. Samples were scanned from $4{ }^{\circ}$ to $90^{\circ}(2 \theta)$ and in stage sizes of 0.0200 , with count time of $0.7 \mathrm{~s}$, using an automatic divergence slit assembly with a proportional detector. The samples were scanned at $25^{\circ} \mathrm{C}$. Relative intensities were read from the strip charts and corrected to fix slit values. X-ray diffraction studies were conducted on pure drug, polymer, Co-polymer, physical mixture and optimized Nano-sponge formula.

\section{Optical microscopy}

A thin layer of aqueous colloidal dispersion was spread on a slide after dilution with a small drop of deionized water then dried. The nature of vesicles was observed and focused under a light microscope (Olympus, Philippines) at various magnification powers $(10 \times$ and $40 \times)$. Photomicrographs were taken using Fujifilm Finepix F 40 fd (8.3 MP) digital camera with $3 \times$ optical zooms.

\section{Particle size and polydispersity}

Particle size measurements of drug-loaded Nano-sponge were performed by Malvern Zeta sizer by dynamic light scattering (Nano ZS, Malvern, and Worcester-shire, UK). Before measurements samples were dispersed in distilled water. Three replicates were measured and values were presented as mean \pm standard deviation (SD).

\section{Zeta potential}

Zeta potential is a logical term for electrokinetic potential in colloidal dispersions and it is the most imperative parameter for physical stability of Nano-sponge. The higher the electrostatic repulsion between the particles more is the stability.

\section{Morphology and surface topography of nano-sponge}

The morphological features of prepared dried Nano-sponge were observed by scanning electron microscopy (SEM) at different magnifications (Hitachi-S 3400N, Japan) at the Center of Agriculture Researches, Cairo University. Also Transmission electron microscopy (TEM) HU-12A (Hitachi Ltd, Mito, Japan) at the Research Park of Faculty of Agriculture, Cairo University was used to 
determine TEM size and shape of drug-loaded Nano-sponge. The samples were dispersed in distilled water before TEM technique.

\section{Entrapment efficiency}

The specified weight of Nano-sponge suspension was analyzed by dissolving the dry sample in $10 \mathrm{ml}$ of distilled water. After drug was dissolved $10 \mathrm{ml}$ of clear layer was taken and amount of drug in the water phase was detected by a UV-spectrophotometric method at $\lambda$ $\max 235 \mathrm{~nm}$. The test was repeated with another Nanoparticulate sample. The amount of drug encapsulated in Nano-sponge was analyzed by cooling centrifugation (Sigma, 3-30KS, Germany)for 30 $\mathrm{min}$ at $15000 \mathrm{r} / \mathrm{min}$ and $4{ }^{\circ} \mathrm{C}$ and by measuring the concentration of drug in the clear supernatant layer by the UV-spectrophotometric method at $\lambda$ max $235 \mathrm{~nm}$. The test was again repeated with another sample. Drug concentration was determined with the help of calibration curve plotted in three different media (deionized water, $0.1 \mathrm{~N} \mathrm{HCl} \mathrm{pH} 1.2$ and phosphate buffer $\mathrm{pH}$ 6.8). The amount of drug inside the particles was calculated by subtracting the amount of drug in the aqueous phase of the colloidal dispersion from the total amount of the drug in the Nano dispersed particles. The entrapment efficiency (\%) of drug was calculated by the following equation.

$$
\text { Drug Entrapment } \%=\frac{\text { Mass of drug in Nano-sponge }}{\text { Mass of drug used in formulation }} \times 100
$$

\section{Loading efficiency}

The loading efficiency (\%) of Nano-sponge can be determined by

$$
\text { Loading Efficiency } \%=\frac{\text { Entrapped drug in Nano-sponge }}{\text { Nano-sponge weight }} \times 100
$$

\section{Production yield}

The production yield (PY) can be determined by calculating initial weight of raw materials used in the formulation and final weight of dried mass Nano-sponge [15].

$$
\% \text { Production Yield }=\frac{\text { Practical mass of Nano-sponge }}{\text { Theoretical mass (drug }+ \text { polymers })} \times 100
$$

\section{Porosity}

Porosity study was performed to check the extent of Nanochannels and Nano cavities formed [16]. The tapped and untapped (bulk) densities were determined by marking a small cuvette with known volume, then inserting a small known mass of powder into the cuvette (bulk density) and tapping it vertically against a padded benchtop 50 times (tapped density) [17]. The mass is divided by the initial and final volumes. True density was determined using ultrapycnometer 1000. True density was calculated by dividing the sample weight by the sample volume [18]. Owing to their porous nature, Nano-sponge exhibit higher porosity compared to the parent polymer and co-polymers used to fabricate the system. Percent porosity is given by equation [19].

$$
\% \text { Porosity }=\frac{\text { True density }- \text { Bulk density }}{\text { True density }} \times 100
$$

\section{Swelling and water uptake}

Swell able polymers Nano-sponge and water uptake was determined by soaking three different weighable mass of each prepared Nanosponge formula in aqueous solvent for $72 \mathrm{~h}$ using graduated Eppendorf. Swelling and water uptake could be calculated using equations [19].

$$
\begin{gathered}
\% \text { Swelling }=\frac{\text { Marking of Eppendorf at a specified time point }}{\text { Initial marking before soaking }} \times 100 \\
\% \text { Water uptake }=\frac{\text { Mass of Nano-sponge after } 72 \mathrm{~h}}{\text { Initial dry mass }} \times 100
\end{gathered}
$$

\section{In vitro drug release studies}

The in vitro release studies of drug-loaded Nano-sponge were carried out in USP type II auto sampler dissolution apparatus (Hansen, Germany) fitted with eight rotating paddle and vessels. Nine formulas were used for release study and the experiments were carried out in triplicate. The rotation speed was $100 \mathrm{r} / \mathrm{min}$ using $600 \mathrm{ml}$ of $0.1 \mathrm{~N}$ HCL (pH 1.2 buffer) for first $2 \mathrm{~h}$ and the remaining $24 \mathrm{~h}$ in phosphate buffer ( $\mathrm{pH} 6.8$ ), $\mathrm{pH}$ changed by adding of $30 \mathrm{gm}$ of Trisodium orthophosphate [20] with sink conditions. Temperature of the dissolution medium was maintained at $37 \pm 0.5$ ${ }^{\circ} \mathrm{C}$. At predetermined time intervals $(0.5,1,1.5$ and $2 \mathrm{~h})$ in $\mathrm{HCl} \mathrm{pH} 1.2$ and at $(0,0.5,1,1.5,2,3,4,5,6,8,12,14,16,18,20,22$, and $24 \mathrm{~h})$ in phosphate buffer $\mathrm{pH} 6.8,2 \mathrm{ml}$ sample was withdrawn and replaced with fresh dissolution media [21]. The samples were analyzed by the UV spectrophotometric method at $\lambda \max 235 \mathrm{~nm}$ and the results were reported. The absorbance of each sample was recorded and percentage drug release was calculated. Calibration curve of nifedipine in each $\mathrm{pH}$ media was used to calculate drug concentrations.

\section{Kinetic studies: mathematical models}

In the present study, data of the in vitro release were fitted to different equations and kinetic models in order to explain the release kinetics of nifedipine from Nano-sponge. The kinetic models used were Zero-order equation, First order, Higuchi release, HixsonCrowell, and Korsmeyer-Peppas models. The best fit with higher correlation $\left(\mathrm{R}^{2}\right)$ was calculated.

\section{Zero-order kinetics}

Drug dissolution from pharmaceutical dosage forms that do not disaggregate and release the drug slowly, assuming that the area does not change and no equilibrium conditions are obtained, can be represented by the following equation:

$\mathrm{Qt}=\mathrm{Qo}+\mathrm{Kot}$

Where $\mathrm{Q} t=$ amount of drug dissolved in time $\mathrm{t}$,

Qo = amount of drug in the dissolution,

Ko $=$ zero-order rate constant.

When the data were plotted as \% drug release versus time, if the plot is linear then data obeys zero-order kinetics with slope equal to Ko. This model represents an ideal release profile in order to achieve prolonged pharmacological action.

\section{First order kinetics}

To study the first order, release rate data were fitted to the following equation:

$$
\log Q t=\log Q o+K 1 t / 2.303
$$

Where $\mathrm{Q} t=$ amount of drug release in time $\mathrm{t}$.

Qo = initial amount of drug in solution.

$\mathrm{K} 1$ = first-order release rate constant.

When data were plotted as log cumulative \% drug remaining verses time yields a straight line indicating that the release follows firstorder kinetics. The constant $\mathrm{K}$ can be obtained multiplying slope values.

\section{Higuchi model}

Higuchi developed several theoretical models to study the release of water-soluble and low soluble drugs incorporate in semisolids and or solid matrices. Mathematical expressions were obtained for drug particles dispersed in a uniform matrix behaving as the diffusion media.

$\mathrm{Q}=\mathrm{K}_{\mathrm{H}} \cdot \mathrm{T}^{1 / 2}$

Where, $Q=$ amount of drug at time $t$,

$\mathrm{KH}=$ Higuchi rate constant. 
When data were plotted according to this equation, i.e. cumulative drug released verses square root of time, yields a straight line, indicating that the drug was released by diffusion mechanism.

\section{Hixson-crowell model}

The release rate data were fitted to the following equation.

$$
\text { Qo } 1 / 3-Q \mathrm{t} 1 /=\mathrm{KHC} \mathrm{t}
$$

Where $\mathrm{Q} t=$ amount of drug release in time $\mathrm{t}$,

Qo = initial amount of drug in tablet,

K H C = rate constant for Hixson-Crowell rate equation.

\section{Korsmeyer-peppas model}

To study this model the release rate data are fitted to the following equation.

$$
\mathrm{Mt} / \mathrm{M} \infty=\mathrm{kt}^{\mathrm{n}}
$$

Where Mt = amount of drug release at time $t$,

$\mathrm{M} \infty=$ amount of drug release after infinite time,

$\mathrm{Mt} / \mathrm{M} \infty=$ factorial drug release $\%$ at time $\mathrm{t}$,

$\mathrm{K}=$ release constant,

$\mathrm{t}=$ release time,

$\mathrm{n}=$ Diffusional exponent for the drug release that is dependent on the slope of the matrix dosage forms.

This is used when the release mechanism is not well known or when more than one type of release phenomenon could be involved [22].

\section{In vivo drug absorption studies}

\section{Study design}

The study was carried out to compare the pharmacokinetics of nifedipine in rabbit plasma following oral administration of Epilat ${ }^{\circledR}$ $10 \mathrm{mg}$ soft gelatin capsules (E. P. I. CO., EGYPT) and the bestachieved drug entrapment efficiency percentage Nano-sponge (F5) using a non-blind, two-treatment, two-period, randomized, crossover design. The use and the treatment of rabbits in this study were conducted in full compliance with the spirit of Association for Assessment and Accreditation of Laboratory Animal Care (AAALAC), International's expectations for animal care and use ethics committees. The protocol of the study (REC-FPESPI-12/80) was approved by the Research Ethics Committee for experimental and clinical studies at the Faculty of Pharmaceutical Sciences and Pharmaceutical Industries, Future University in Egypt.

\section{Animals}

Six healthy albino male rabbits (weighing 2-2.5 kg) were housed in an air-conditioned room under controlled alternate day and night cycles; provided with artificial fluorescent light. The animals were fed standard pellet diet, water and libitum. These conditions were evaluated on a daily basis to ensure the safety and well-being of an animal. A veterinarian checked the health of animals to ensure the lack of clinically observable abnormalities.

\section{Administration of drug treatment to rabbits}

After overnight fasting, the rabbits randomly divided into two equal groups. Each rabbit of the first group was administered sample of drug-loaded Nano-sponge (F5) equivalent to $20 \mathrm{mg}$ nifedipine (Test, treatment A) after dispersion in $10 \mathrm{ml}$ distilled water. Meanwhile, the rabbits of the other group received conventional marketed Epilat ${ }^{\circledR}$ soft gelatin capsules after evacuation contained the same previous nifedipine dose (Reference, treatment B). Before withdrawal of blood samples, the marginal ear vein was dilated, using warm water and swapping with cotton, and then punctured (24 gauge needle) to allow withdrawal of blood samples $(2 \mathrm{ml})$ at 0 time (pre-dose), 0.5, 1, 1.5, 2, 3, 4, 6, 8, 12, 24 and $48 \mathrm{~h}$ (post-dose). The samples were collected in EDTA tubes to prevent blood coagulation, followed by centrifugation $(3000 \times \mathrm{g})$ for $10 \mathrm{~min}$ to separate plasma. The samples were frozen in- $20{ }^{\circ} \mathrm{C}$ refrigerator till analyzed. After $14 \mathrm{~d}$ washing up period, the test was repeated using cross over design.

\section{Chromatographic conditions}

HPLC; Parkin Elmer equipped with variable wavelength UV detector and autosampler, USA. The column used was C18, $250 \mathrm{~mm} \times 4.6 \mathrm{~mm}$, $5 \mu \mathrm{m}$ Phenomenex kinetex. Acetonitrile: Water (60:30 v/v) used as mobile phase and $\mathrm{pH}$ was adjusted to 3.0 with orthophosphoric acid. The injection volume was $40 \mu \mathrm{l}$ with Flow Rate $1 \mathrm{ml} / \mathrm{min}$. The UV detector with variable wavelength adjusted at $235 \mathrm{~nm}$. Winchrom was used as chromatographic data analysis program.

\section{Preparation of stock solutions}

Nifedipine standard stock solution was prepared by dissolving 10 mg accurately weighed of pure drug in $100 \mathrm{ml}$ of acetonitrile in 100ml-volumetric flask to obtain a concentration of $100 \mu \mathrm{g} / \mathrm{ml}$ nifedipine stock solution. The stock solution was diluted with acetonitrile to obtain working solutions ranging from $50-800 \mathrm{ng} / \mathrm{ml}$. Diclofenac standard stock solution was prepared by dissolving 10 mg accurately weighed of the compound in $100 \mathrm{ml}$ of acetonitrile in $100-\mathrm{ml}$-volumetric flask to obtain concentration of $100 \mu \mathrm{g} / \mathrm{ml}$ stock solution. Diclofenac stock solution was diluted with acetonitrile to obtain working solution of $100 \mathrm{ng} / \mathrm{ml} \mathrm{[23].}$

\section{Sample processing}

For calibration measurements, deep-frozen plasma was thawed at ambient temperature and $1 \mathrm{ml}$ portions were pipette into centrifuge tubes covered with aluminum foil. $50 \mu 1$ of the calibration solutions and $200 \mu \mathrm{l}$ of $1 \mathrm{M} \mathrm{NaOH}$ solution were added to the plasma and after mixing, $3 \mathrm{ml}$ of the extraction solvent mixture $(70 \% \mathrm{v} / \mathrm{v} \mathrm{n}$ hexane $+30 \% \mathrm{v} / \mathrm{v}$ dichloromethane) (30:70 v/v) was added. Following agitation on a vortex mixer for $30 \mathrm{~s}$ and centrifuging at $3000 \mathrm{r} / \mathrm{min}$ for $15 \mathrm{~min}$ in the dark, $2 \mathrm{ml}$ of the organic phase were transferred to a test tube covered with aluminum foil. The solvent was evaporated at $30^{\circ} \mathrm{C}$ under a stream of high purity nitrogen using a test-tube thermostat. The residue was reconstituted in $200 \mu 1$ of the mobile phase and 50 $\mu 1$ were injected into the chromatographic system. Samples evaporated to dryness were stored in a closed dark box until measured. The peak heights of nifedipine and the internal standard and the ratios of the peak heights were determined [24].

For measurement of nifedipine in rabbit's plasma samples, the frozen samples were thawed at ambient temperature and $200 \mu \mathrm{l}$ of 1 $\mathrm{M} \mathrm{NaOH}$ solution were added to each plasma sample and after mixing, $3 \mathrm{ml}$ of the extraction solvent mixture $(70 \% \mathrm{v} / \mathrm{v} \mathrm{n}$ hexane $+30 \% \mathrm{v} / \mathrm{v}$ dichloromethane) $(30: 70 \mathrm{v} / \mathrm{v})$ was added then the following steps were repeated as previously mentioned above [25].

\section{Pharmacokinetic and statistical analyses}

The pharmacokinetic (PK) parameters following oral administration of both treatments for each animal in cross over design were estimated based on the non-compartmental analysis using residual method soft wear program. The estimated pharmacokinetic parameters included; $\mathrm{C}_{\max }$ (the maximum drug concentration; $\mathrm{ng} / \mathrm{ml}$ ), $\mathrm{T}_{\max }$ (the time to reach $\mathrm{C}_{\max } ; \mathrm{h}$ ), $\mathrm{AUC}_{0-48 \mathrm{~h}}$ (the area under the plasma concentration-time curve from zero to $48 \mathrm{~h} ; \mathrm{ng} \mathrm{h} / \mathrm{ml}$ ), $\mathrm{AUC}_{0}$. $\infty$ (the area under the curve from zero to infinity; ng h/ml), $\mathrm{t}_{1 / 2}$ (plasma elimination half-life; $h$ ), $\mathrm{K}_{\mathrm{ab}}$ (absorption rate constant; $\mathrm{h}^{-1}$ ), $\mathrm{K}_{\mathrm{el}}$ (elimination rate constant; $\mathrm{h}^{-1}$ ), Vd (apparent distribution volume; $\mathrm{L}$ ) and $\mathrm{T}_{\mathrm{cl}}$ (total body clearance; $\mathrm{ml} / \mathrm{min}$ ) [26]. In addition to AUMC (area under the first-moment curve; ng $\mathrm{h}^{2} / \mathrm{ml}$ ), MRT (mean residence time; $h$ ) and $C_{\max }$ /AUC ratio; $h^{-1}$. The results are expressed as mean values of six rabbit's \pm SD the statistical significance of the results was checked using one-way ANOVA Tukey compare test (MSDOS program) at a P-value of 0.05 .

\section{Toxicological consideration; in vitro cytotoxicity}

Determination of sample cytotoxicity on cell culture (MTT protocol)

A MTT (3-(4, 5-dimethylthiazol-2-yl)-2,5-diphenyltetrazolium bromide) assay was performed to determine the cytotoxic effects of 
optimized Nano-sponge formula loaded with nifedipine on human normal kidney and liver cells were purchased from the ATCC (American Type Culture Collection, CCL-75 $5^{\mathrm{m}}$ ) [27]. A 96 well tissue culture plate was inoculated with 1 X $10^{5} \mathrm{cells} / \mathrm{ml}$ (100 ul/well) and incubated at $37^{\circ} \mathrm{C}$ for $24 \mathrm{~h}$ to develop a complete monolayer sheet. Growth medium was decanted from 96 well microtiter plates after confluent sheet of cells were formed, cell monolayer was washed twice with wash media. Two-fold dilutions of tested sample were made in RPMI medium with 2\% serum (maintenance medium). 0.1 $\mathrm{ml}$ of each dilution was tested in different wells leaving 3 wells as control, receiving only maintenance medium. Plate was incubated at $37^{\circ} \mathrm{C}$ and examined. Cells were checked under inverted microscope for any physical signs of toxicity, e. g. partial or complete loss of the monolayer, rounding, shrinkage, or cell granulation. MTT solution was prepared (5 mg/ml in PBS) (BIO BASIC CANADA INC). 20ul MTT solution was added to each well. Plate Placed on a shaking table at $150 \mathrm{r} / \mathrm{min}$ for $5 \mathrm{~min}$, to thoroughly mix the MTT into the media then Incubation at $37^{\circ} \mathrm{C}$ and $5 \% \mathrm{CO} 2$ humidified atmosphere for $1-5 \mathrm{~h}$ to allow the MTT to be metabolized. The media Dumped off then the plate was dried on paper towels to remove any residue. Formazan (MTT metabolic product) was re-suspended in 200ul DMSO and placed on a shaking table at $150 \mathrm{r} / \mathrm{min}$ for $5 \mathrm{~min}$, to thoroughly mix the formazan into the solvent. Optical densities (O. D) were read at $560 \mathrm{~nm}$ using a multiwall microplate reader (Synergy HT, Biotech, France,) and subtract background at $620 \mathrm{~nm}$. Optical density should be directly correlated with cell quantity. Half maximal inhibitory concentration IC50 was calculated for each cell type in addition to viability $\%$ and toxicity $\%$. The experiment was performed in triplicate, and the result was expressed as mean \pm SD

$$
\text { Viability } \%=\frac{\text { Average of O.D. of tested sample }}{\text { O.D. of control cells }} \times 100
$$

Toxicity $\%=100$-Viability $\%$

\section{Hemolytic assay}

Hemolytic assay was carried out by adopting the method of Bulmus et al., 2003 [28]. Freshly collected human red blood cells were taken and washed three times by $150 \mathrm{mmol} \mathrm{NaCl}$ using centrifuge at 2500 $\mathrm{r} / \mathrm{min}$ for $10 \mathrm{~min}$. The plasma was removed and the cells were suspended in phosphate buffer saline $\mathrm{pH} \mathrm{7.4)} \mathrm{for} \mathrm{made} \mathrm{2 \%} \mathrm{RBCs}$ concentration. Double folded dilutions concentrations (20000, $10000,5000, \ldots ., 0.61 \mu \mathrm{g} / \mathrm{ml}$ ) of nifedipine Nano-sponge was mixed with $2 \% \mathrm{~L}$ of $\mathrm{RBC}$ solutions and the final reaction mixture volume was made up to $1 \mathrm{ml}$ by adding sodium phosphate buffer. The reaction mixture was then placed in a water bath for $1 \mathrm{~h}$ at $37^{\circ} \mathrm{C}$. After the incubation time the reaction mixture was centrifuged again at $2500 \mathrm{r} / \mathrm{min}$ for $15 \mathrm{~min}$. The supernatant was collected and the optical density was measured at $541 \mathrm{~nm}$, keeping phosphate buffer saline as blank. Deionized water was used as a positive control. The experiment was done in triplicate and mean $\pm \mathrm{SD}$ was calculated.

Percentage hemolysis $=\frac{(\text { Absorbance of sample-Absorbance of blank })}{\text { Absorbance of positive control }} \times 100$

\section{RESULTS AND DISCUSSION}
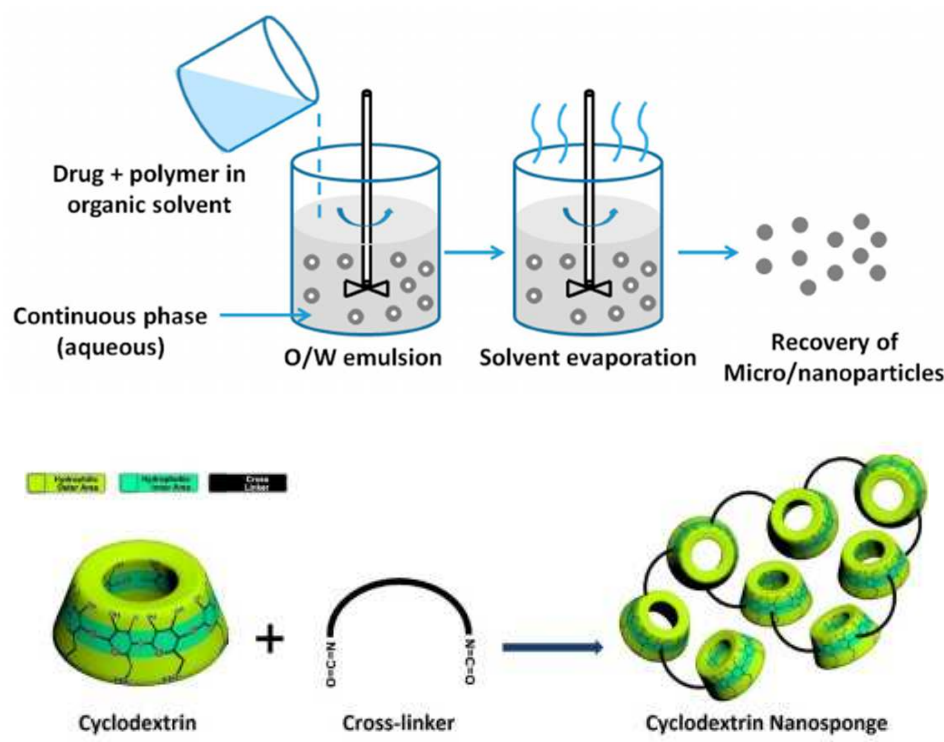

Fig. 2: Emulsion solvent evaporation technique

\section{Particle size analysis of nano-sponge}

The particle size distribution of the Nano-sponge was determined by Zeta sizer and the Nano-sponge were found to be uniform in size. Free-flowing powders with fine aesthetic attributes are possible to obtain by controlling the size of particles during polymerization. The average particle size of all formulations range from $119.1 \pm 137.6 \mathrm{~nm}$ to $529.0 \pm 33.38 \mathrm{~nm}$ as shown in table 2 which is in increasing order due to the increase in the concentration of polymer but it was observed that as the ratio of drug: polymer was increased, the particle size decreased. This could probably be due to the fact that at higher relative drug content, the amount of polymer available per Nano-sponge was comparatively less. Probably in high drug: polymer ratios less polymer amounts encapsulated the drug and reducing the thickness of polymer wall and Nano-sponge with smaller size was obtained. Probably emulsion of high surface area and small droplets size were formed with high stirring rate and Nano-sponge with smaller size were formulated. By performing the particle size analysis, it is concluded that the formulations had the particle size varies with the concentration of polymer to drug ratio. Polydispersity for formulas was ranged from $0.164 \pm 0.008$ to $0.293 \pm 0.018$ indicating uniform particle size distributions and homogeneity of the prepared formulas. Zeta potential was negative sign and ranged from- $9.8 \pm 3.38$ to- $28.8 \pm 0.283 \mathrm{mV}$ ensure stability for longer period of time. Low potential values were observed for formulas prepared with PVA indicating steric hindrance stabilization, while high values were observed for formulas prepared with $\beta$-cyclodextrin and HP $\beta$-cyclodextrin pointed to electrostatic repulsive stabilization and prevention of particles aggregation [29]. 
Table 2: Particle size of nifedipine Nano-sponge; $(n=3)$

\begin{tabular}{llll}
\hline S. No. & TEM size d. nm & Malvern zeta sizer d. nm & PDI \\
\hline F1 & $117.16 \pm 87.79$ & $119.1 \pm 137.6$ & $0.164 \pm 0.008$ \\
F2 & $149.08 \pm 90.02$ & $308.1 \pm 62.58$ & $0.293 \pm 0.018$ \\
F3 & $230.35 \pm 21.83$ & $529.0 \pm 33.38$ & $0.268 \pm 0.001$ \\
F4 & $94.76 \pm 22.27$ & $165.3 \pm 12.51$ & $0.281 \pm 0.024$ \\
F5 & $110.80 \pm 39.50$ & $181.6 \pm 27.79$ & $0.189 \pm 0.016$ \\
F6 & $170.61 \pm 11.51$ & $279.3 \pm 38.42$ & $0.259 \pm 0.008$ \\
F7 & $60.28 \pm 19.49$ & $167.1 \pm 2.899$ & $0.252 \pm 0.001$ \\
F8 & $95.79 \pm 33.97$ & $248.7 \pm 6.788$ & $0.289 \pm 0.033$ \\
F9 & $120.90 \pm 13.68$ & $513.3 \pm 27.44$ & $0.245 \pm 0.052$ \\
\hline
\end{tabular}

$\mathrm{n}=$ number of determination; mean \pm Standard Deviation

\section{Morphology determination by optical and electron microscopy}

The morphology of the Nano-sponge prepared by emulsion solvent evaporation technique was investigated by optical microscope, TEM and SEM. It was observed that the Nano-sponge were spherical, and uniform with smooth texture and no drug crystals on the surface as shown in fig. 3 by each of optical and Transmission electron microscope. SEM analysis showed that the Nano-sponge were uniformly spherical in shape with spongy and porous nature that cavities were clear in the center of spherical. Average particle size of Nano-sponge measured by TEM was found to be smaller than measuring with Zeta sizer which average ranged from $60.28 \pm 19.49$ $\mathrm{nm}$ to $230.35 \pm 21.83 \mathrm{~nm}$. This is maybe attributed to the difference in the principles underlying these techniques. Thus Zeta sizer allowed the observation of Nano-sponge in a hydrated colloidal state. For TEM the sample was dried at $55^{\circ} \mathrm{C}$. Thus, particle sizes were recorded via different techniques were found to be in the following order $\mathrm{TEM}<$ Zeta sizer, some reference is consistent with this result [30].

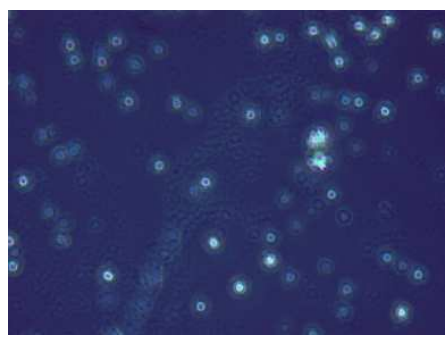

(A)
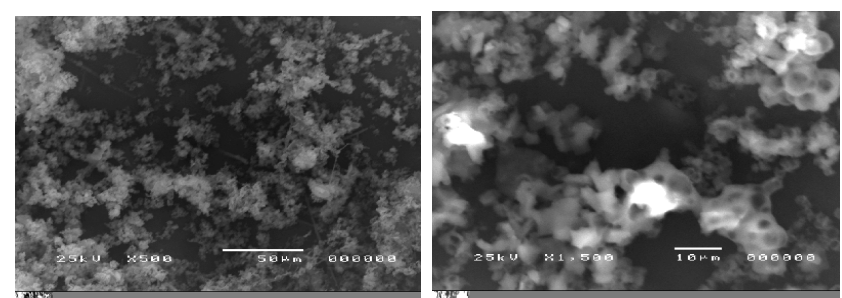

(B)
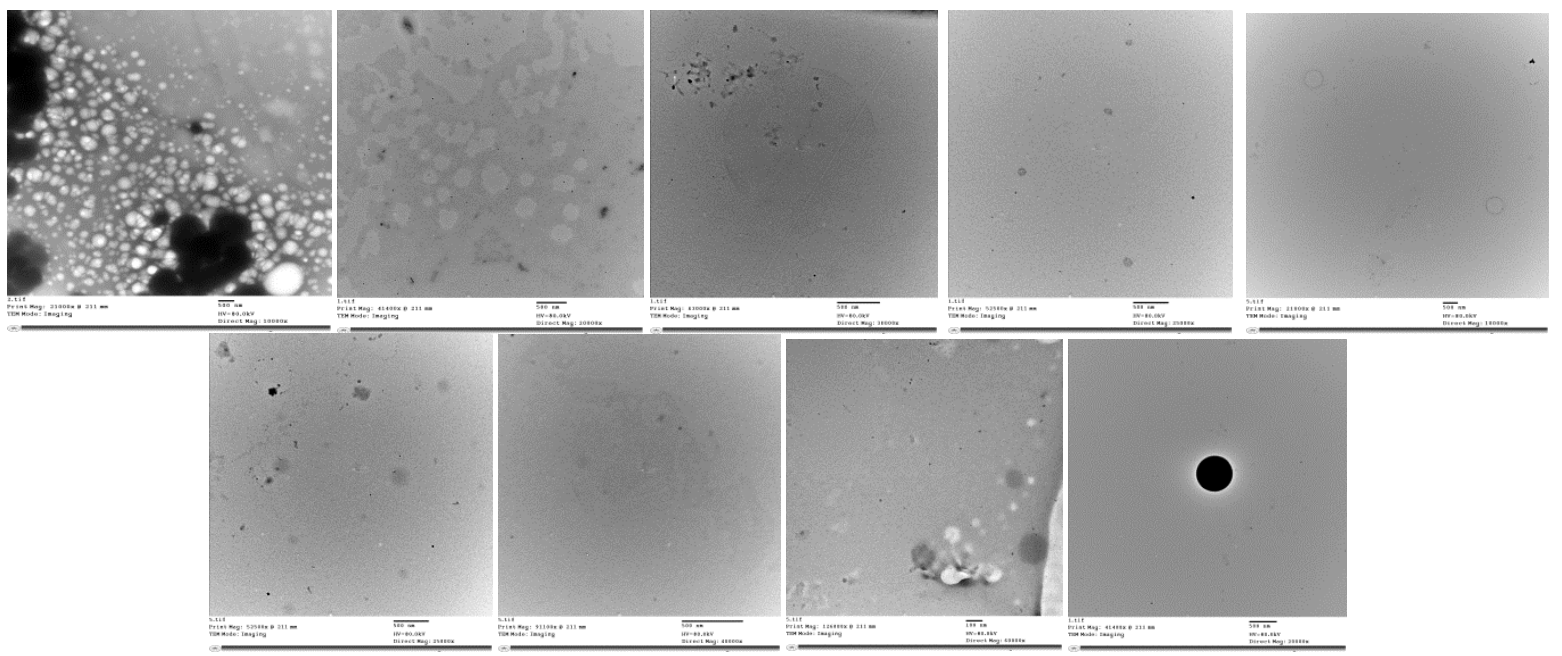

(C)

Fig. 3: (A) optical view of F5 Nano-sponge, (B) SEM image of F5 Nano-sponge, (c) TEM image of nine formulas in order starting from lift to right $F 1, F 2, F 3, F 4, F 5, F 6, F 7, F 8$ and $F 9$ 


\section{Percentage of drug content}

The percentage drug content of the formulated Nano-sponge (F1-F9) as shown in table 3 was found in the mean range from minimum $77.99 \pm 0.24 \%$ to maximum $94.75 \pm 0.43 \%$. The percentage of drug content of formulation $\mathrm{F} 1$ was found to be $84.42 \pm 0.32 \%$, formulation F2 was found to be $81.82 \pm 0.10 \%$, formulation F3 was found to be $83.33 \pm 0.42 \%$, formulation $\mathrm{F} 4$ was found to be $83.22 \pm 0.02 \%$, formulation F5 was found to be $94.75 \pm 0.43 \%$, and formulation F6 was found to be $90.96 \pm 0.51 \%$, formulation F7 was found to be $77.99 \pm 0.24 \%$, formulation F8 was found to be $86.17 \pm 0.07 \%$, and F9 Formulation was found to be $87.31 \pm 0.13 \%$. High percentage drug content proved high Nano-sponge capacity for drug encapsulation owing to porous polymeric nature.

Table 3: Measurements of drug encapsulation characters; $(n=3)$

\begin{tabular}{llll}
\hline S. No. & EE\% & \%Drug loading & \%Drug content \\
\hline F1 & $84.53 \pm 1.02$ & $40.24 \pm 0.147$ & $84.42 \pm 0.32$ \\
F2 & $91.85 \pm 2.21$ & $36.74 \pm 0.932$ & $81.82 \pm 0.10$ \\
F3 & $93.84 \pm 1.56$ & $31.28 \pm 0.530$ & $83.33 \pm 0.42$ \\
F4 & $86.96 \pm 2.87$ & $38.65 \pm 0.712$ & $83.22 \pm 0.02$ \\
F5 & $96.63 \pm 1.01$ & $43.48 \pm 0.120$ & $94.75 \pm 0.43$ \\
F6 & $91.12 \pm 2.45$ & $30.375 \pm 0.746$ & $90.96 \pm 0.51$ \\
F7 & $82.72 \pm 1.33$ & $41.369 \pm 3.079$ & $77.99 \pm 0.24$ \\
F8 & $84.96 \pm 2.89$ & $33.986 \pm 1.686$ & $86.176 \pm 0.07$ \\
F9 & $84.67 \pm 0.19$ & $28.273 \pm 0.087$ & $87.318 \pm 0.13$ \\
\hline
\end{tabular}

$\mathrm{n}=$ number of determination; mean \pm Standard Deviation

\section{Entrapment efficiency and drug loading}

The drug entrapment efficiency percentage of Nano-sponge formulations are given in table 3. The loading efficiency calculated for all formulas ranged from $43.48 \pm 0.120 \% \mathrm{w} / \mathrm{w}$ to $28.273 \pm 0.087 \%$ $\mathrm{w} / \mathrm{w}$ presenting the highest loading efficiency was found for the F5 formula where a greater amount of drug was encapsulated. The highest loading efficiency, greater the amount of drug was encapsulated. This could be attributed to the highest drug loading and optimum degree of cross-linking. The entrapment efficiency $\%$ was affected by drug: polymer molar ratios and changed when drug and polymer ratio has been changed. The entrapment efficiency of formulation F1 was found to be $84.53 \pm 1.02 \%$, formulation F2 was found to be $91.85 \pm 2.21 \%$, formulation F3 was found to be $93.84 \pm 1.56 \%$, formulation $\mathrm{F} 4$ was found to be $86.96 \pm 2.87 \%$, formulation F5 was found to be $96.63 \pm 1.01 \%$, and formulation F6 was found to be $91.12 \pm 2.45 \%$, formulation F7 was found to be $82.72 \pm 1.33 \%$, formulation F8 was found to be $84.96 \pm 2.89 \%$, and F9 was found to be $84.67 \pm 0.19 \%$. Among all the formulations F5 showed highest entrapment efficiency of $96.63 \pm 1.01 \%$, while F7 had the lowest EE\% of $82.72 \pm 1.33 \%$. Drugs can be loaded into the Nanosponge cavities while they are in the solution state. Factors affecting drug loading and release from Nano-sponge have been well documented. The two important parameters investigated include the type and molar ratio of cross-linker used and the process of synthesis. The crystalline state of Nano-sponge varies with reaction conditions which further affects the amount of drug entrapment.

\section{Production yield, porosity and swelling}

The production yield is a measure of the accuracy of the technique, since it measures the actual weight of the prepared Nano-sponge (drug+polymer+co-polymer). This value was calculated by dividing the actual weight of the prepared Nano-sponge by the theoretical weight. The range of the production yield of the prepared Nanosponge was found to be between $62.1 \pm 0.92 \%$ and $92.4 \pm 0.48 \%$ as shown in table 4. The highest value appeared in formula F5 $92.4 \pm 0.48$ while the less value appeared in formula F9. It was observed that Increase in the drug/polymer molar ratios (1:1 to $1: 3$ ) affected and changed their yield and may increase due to the increase in the concentration of polymer. Tansel Comoglu, et al. [31] clarified in their study that the dispersion of the drug and polymer into the aqueous phase was found to be dependent on the agitation speed. As the speed was increased, the size of Nano-sponge was reduced and was found to be spherical and uniform. When the rate of stirring was increased up to $1000 \mathrm{r} / \mathrm{min}$ the spherical Nanosponge were formed with mean particle size of about $300 \mathrm{~nm}$. They noted that at higher stirring rate the production yield was decreased. Possibly, at the higher stirring rates the polymer adhered to paddle due to the turbulence created within the external phase, and hence production yield decreased [32]. Bulk and tapped densities were measured for nine dried Nano-sponge formulas. Bulk densities ranged from $0.2240 \mathrm{~g} / \mathrm{cm}^{3}$ to $0.3530 \mathrm{~g} / \mathrm{cm}^{3}$. While the taped densities ranged from $0.2948 \mathrm{~g} / \mathrm{cm}^{3}$ to $0.4353 \mathrm{~g} / \mathrm{cm}^{3}$. All formulas had a high percentage of porosity, swelling and water uptake due to spongy and porous nature. The Nano-sponge system has pores, that increase the rate of water uptake and hence solubilization of poorly soluble drug by entrapping such drugs in pores. Due to Nano size, surface area significantly increased and increase rate of solubilization of drugs having low solubility, and a dissolution rate-limited poor bioavailability [33]. Nano-sponge solubilize drug by possibly masking the hydrophobic groups, by increasing the wetting of the drug, and/or by decreasing the crystallinity of the drug [34]. $\beta$-Cyclodextrin cross-linking is a condensation polymerization reaction which requires region-selective addition of reagents, optimized reaction conditions and separation of product by efficient removal of by-products. Cyclodextrin is heated in solution with small molecules called cross-linkers that act like tiny grappling hooks to fasten different parts of the polymer together. The objective is to form spherically shaped particles filled with cavities where drug molecules can be incorporated and stored. The mechanism behind this reaction is nucleophilic attack at the $\mathrm{OH}$ groups by functionalities such as carbonate ion, azide ions, halide ions, thiols, thiourea, anhydrides and amines; this reaction requires activation of the oxygen atom by an electron-withdrawing group. Nano-sponge has been synthesized by substituting hydrogen of the primary hydroxyl groups present on the outer cavity of the parent $\beta$ cyclodextrin, thus forming Nano-cavities for drug entrapment. Moreover, the Nanochannels which are formed due to cross-linking further enhance solubilization, stability and modify drug release [35, 36].

\section{Thermal analysis}

\section{DSC}

The thermograms (DSC) of drug, polymer, co-polymer, drugpolymers physical mixture and Nano-sponge were presented in fig. 4. The DSC curve of pure nifedipine showed a melting endothermic peak at $172.36^{\circ} \mathrm{C}$, while the physical mixture of drug and polymer exhibited an endothermic peak at $171.75^{\circ} \mathrm{C}$. Thus, by comparing the thermograms of drug and drug-polymer it was found that it has a suitable compatibility for further formulation. DSC thermogram of ethylcellulose showed an exothermic peak at $50.3{ }^{\circ} \mathrm{C}$ which was mainly due to the crystallization temperature of the sample. The second exothermic inflection was observed on higher temperature at $344.46{ }^{\circ} \mathrm{C}$ which can be attributed to thermal degradation of EC. The DSC of physical mixture, EC also displayed similar two exothermic peaks behavior, the first peak was due to crystallization temperature $85.06{ }^{\circ} \mathrm{C}$ and the second peak at $323.33{ }^{\circ} \mathrm{C}$ 
corresponded to thermal decomposition of EC. The result showed increase in crystallization temperature by $40.86 \%$ in EC. It is assumed here that the internal energy of treated EC atoms has altered, which caused change in crystallization temperature. DSC thermal analysis of $\beta$-cyclodextrine showed three exothermic peaks, first at $88.53{ }^{\circ} \mathrm{C}$ indicating dehydration, second at $113.55^{\circ} \mathrm{C}$ around its melting point, third at $312.32{ }^{\circ} \mathrm{C}$ for decomposition of copolymer. In physical mixture degradation temperature was shifted to $290.15^{\circ} \mathrm{C}$, with $7 \%$ decrease in decomposition temperature. DSC of prepared Nano-sponge F5 showed that the melting peak of nifedipine disappeared. This indicated that nifedipine was dissolved and encapsulated within the polymer. The crystallization and decomposition temperature of EC appeared at $79.89^{\circ} \mathrm{C}$ and 340.60 ${ }^{\circ} \mathrm{C}$ respectively.

The three peaks of $\beta$-cyclodextrine have appeared at $104.65{ }^{\circ} \mathrm{C}$, $239.81^{\circ} \mathrm{C}$ and $301.79{ }^{\circ} \mathrm{C}$ indicating shift in the dehydration, melting and decomposition temperature. Thermal analysis of drug-loaded Nano-sponge showed decrease in the drugs crystallinity, higher thermodynamic energy, and enhancement of the amorphous property of the drug [37].

Table 4: Measurement of Nano-sponge characters; $(n=3)$

\begin{tabular}{lllll}
\hline S. No. & \%Production yield & \% Porosity & \% Swelling & \% Water uptake \\
\hline F1 & $82.5 \pm 0.23$ & $0.727 \pm 0.007$ & 150 & 306.25 \\
F2 & $70.0 \pm 0.56$ & $0.747 \pm 0.005$ & 133 & 365.71 \\
F3 & $80.0 \pm 0.18$ & $0.760 \pm 0.011$ & 125 & 250.00 \\
F4 & $87.2 \pm 1.36$ & $0.737 \pm 0.014$ & 125 & 192.30 \\
F5 & $92.4 \pm 0.48$ & $0.781 \pm 0.001$ & 150 & 317.85 \\
F6 & $90.3 \pm 0.87$ & $0.728 \pm 0.008$ & 180 & 33.33 \\
F7 & $65.5 \pm 0.77$ & $0.758 \pm 0.011$ & 150 & 200.29 \\
F8 & $78.2 \pm 0.15$ & $0.726 \pm 0.006$ & 128 & 444.44 \\
F9 & $62.1 \pm 0.92$ & $0.775 \pm 0.008$ & & \\
\hline
\end{tabular}

$\mathrm{n}=$ number of determination; mean \pm Standard Deviation

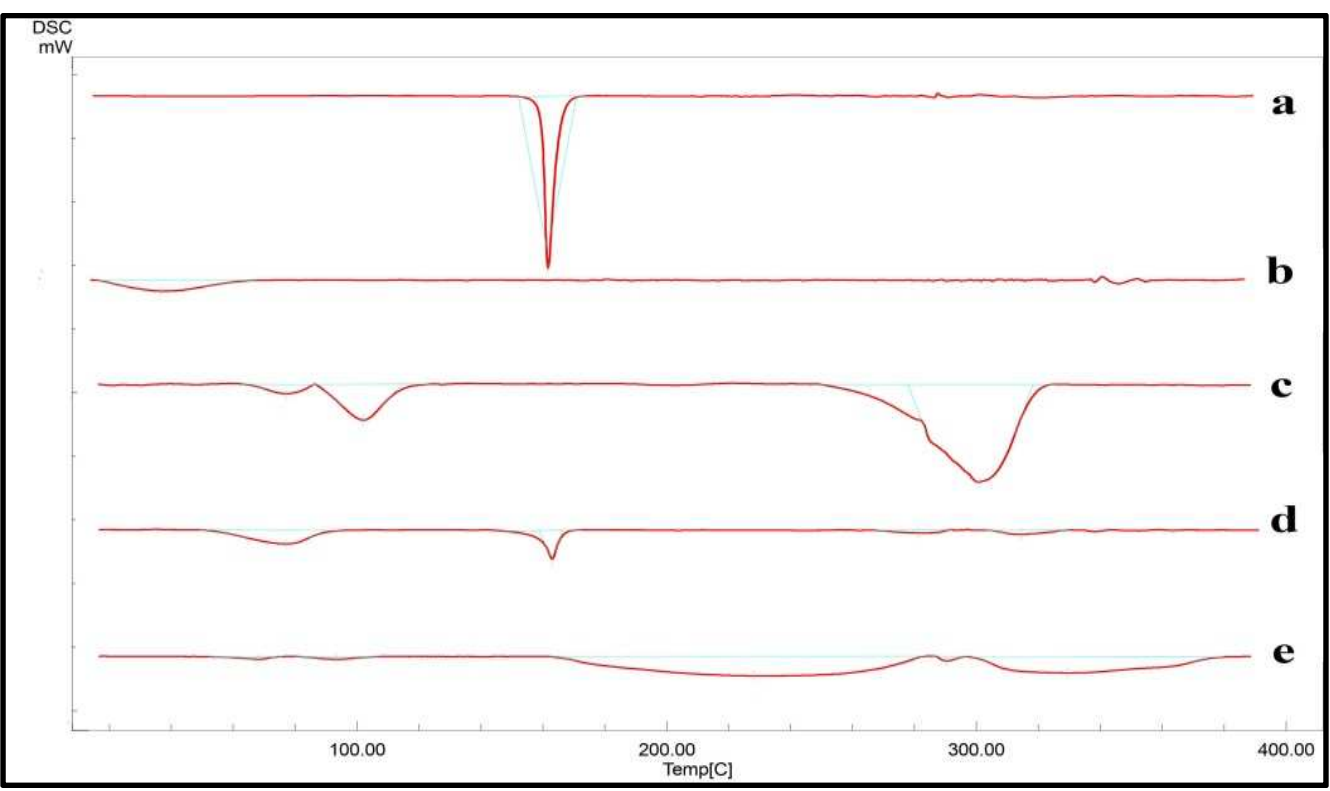

Fig. 4: DSC Thermogram of (a) Nifedipine, (b) EC (Ethyl cellulose), (c) $\beta$ Cyclodextrine, (d) physical mixture, (e) Nanosponge formul

\section{FTIR}

FTIR spectra shown in fig. 5 envisaged the characteristic peaks of nifedipine at $3329.14 \mathrm{~cm}^{-1}, 1681.93 \mathrm{~cm}^{-1}$ and $1226.73 \mathrm{~cm}^{-1}$ represented that--NH stretching, $\mathrm{C}=0$ stretching and $\mathrm{C}-\mathrm{-O}$ bending groups of dihydropyridine. Same characteristic functional groups of nifedipine were appeared at $3329.14 \mathrm{~cm}^{-1}, 1681.93 \mathrm{~cm}^{-1}$ and $1226.73 \mathrm{~cm}^{-1}$ respectively in physical mixture with insignificant shifting of wave numbers. FT-IR of EC showed characteristic peaks at $2978.9 \mathrm{~cm}^{-1}$ and $2877.79 \mathrm{~cm}^{-1}$ due to $\mathrm{C}-\mathrm{H}$ stretching vibration peak. The- $\mathrm{OH}$ stretching vibration peak was observed at 3479.58 $\mathrm{cm}^{-1}$. The other important peaks at $1064.71 \mathrm{~cm}^{-1}$, and $1377.17 \mathrm{~cm}^{-1}$ corresponded to $\mathrm{C}-\mathrm{O}-\mathrm{C}$ stretching and $\mathrm{C}-\mathrm{H}$ bending respectively [38]. The FT-IR spectrum of physical mixture sample showed the same peaks for C-H stretching at $2978.9 \mathrm{~cm}^{-1}, 2877.79 \mathrm{~cm}^{-1}$ and$\mathrm{OH}$ stretching peak was evidenced at $3441.01 \mathrm{~cm}^{-1}$. Vibration peaks at $1026.13 \mathrm{~cm}^{-1}$ and $1381.03 \mathrm{~cm}^{-1}$ were mainly due to $\mathrm{C}-\mathrm{O}-\mathrm{C}$ stretch and C-H bending, respectively. The result showed that C-O-
C stretch present in EC at $1064.71 \mathrm{~cm}^{-1}$ was shifted downward to $1026.13 \mathrm{~cm}^{-1}$. The FTIR spectrum of $\beta$ cyclodextrine showed a characteristic peak at $3645.46 \mathrm{~cm}^{-1}$ and $3583.74 \mathrm{~cm}^{-1}$-due to the $\mathrm{O}-\mathrm{H}$ group stretching. An intense peak at $2927.94 \mathrm{~cm}^{-1}$ due to $\mathrm{C}-\mathrm{H}$ asymmetric/symmetric stretching was also seen. In addition, a peak at $1635.64 \mathrm{~cm}^{-1}$ represented the $\mathrm{H}-\mathrm{O}-\mathrm{H}$ deformation bands of water present in $\beta$ cyclodextrine. Peak at $1157.29 \mathrm{~cm}^{-1}$ indicated $\mathrm{C}-\mathrm{H}$ overtone stretching and another peak at 1029.99 $\mathrm{cm}^{-1}$ indicated $\mathrm{C}-\mathrm{H}, \mathrm{C}-\mathrm{O}$ stretching. As expected, all the FTIR spectra of the $\beta$ cyclodextrine were identical with the physical mixture. All the sharp peaks belonging to $\beta$ cyclodextrine and ethyl cellulose observed in physical mixture were the same in Nano formula. Thus, FTIR study of formulated Nano-sponge F5 demonstrated that there were no chemical interactions articulated between drug and polymers used in the formulation as there were no chemical bonds established between nifedipine and carriers other than hydrogen bonding which was evidenced as change in the wavenumbers of FT-IR spectrum. 


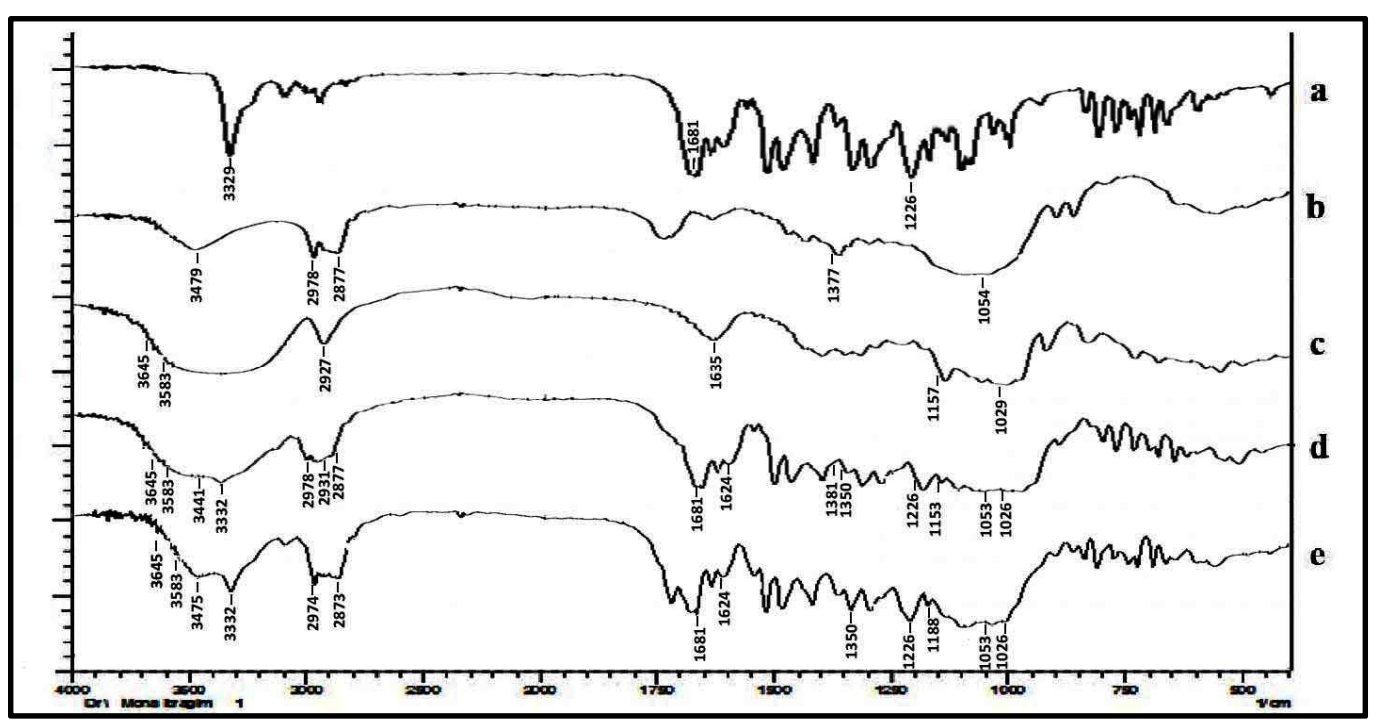

Fig. 5: FTIR Diagram of (a) Nifedipine, (b) EC (Ethyl cellulose), (c) $\beta$ Cyclodextrine, (d) physical mixture, (e) Nano-sponge formula

\section{Powder X-ray diffractometers}

X-ray powder diffraction (XRPD) has been used for evaluating the crystallinity of Nano-sponge and its drug complexation capacity [39]. Changes in crystallinity have a profound effect on drug loading, solubility, dissolution and drug release kinetics. XRPD diffractograms of nifedipine, ethylcellulose, $\beta$ cyclodextrin, physical mixture and nifedipine loaded Nano-sponge were illustrated in fig. 6 in order to outline the different behavior between the experimentally obtained complexes, physical mixture and the simulated ones. The XRPD profile of nifedipine loaded Nano-sponge indicates that the material is low crystalline. Broad peaks in a diffractogram at around $11.8^{\circ}, 19.6^{\circ}$, and $23.9^{\circ}$ were observed. Pure nifedipine and individual polymers were in the crystalline state as known from sharp peaks. Decrease in the peaks intensity and baseline shift of diffractogram were observed due to presence of polymers in Nano-sponge when compared to the physical mixture of nifedipine along with ethylcellulose and $\beta$ cyclodextrin. This might be due to decrease in crystalline of drug. EC showed peaks at $2 \theta$ equals to $11.04^{\circ}$ and $20.31^{\circ}$, the XRPD of treated EC showed peaks at $2 \theta$ equal to $12.25^{\circ}$ and $22.28^{\circ}$. This clarified no significant change in XRPD pattern of treated EC with respect to control in addition to semi-crystalline nature of EC of each control and treated polymer.

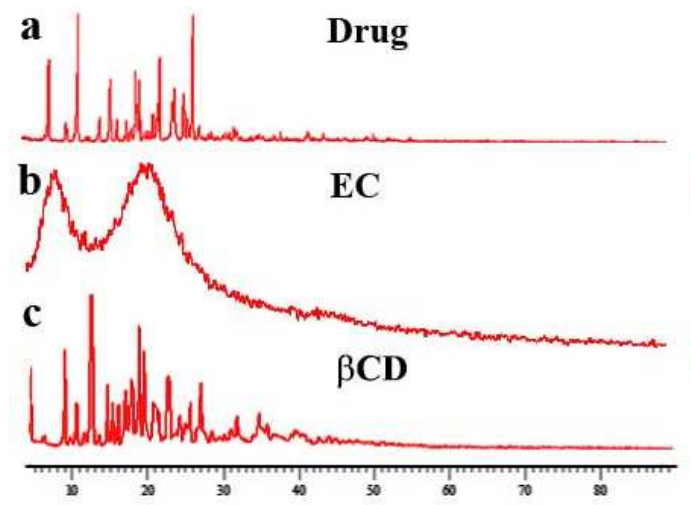

The diffractogram of the simple mixture was the sum of the spectral lines of both of the components that were present. However, the diffractogram of the $\beta$-CD complex exhibited the disappearance of some of the spectral lines at $2.96^{\circ}, 3.56^{\circ}$ and $4.94^{\circ}(2 \theta)$. Additionally, the appearance of new lines was observed including weak lines at $8.33^{\circ}, 7.51^{\circ}$ and $7.11^{\circ}(2 \theta)$ and an intense line at $19.92(2 \theta)$, indicating the presence of new solid crystalline phases that correspond to an inclusion complexes of the same nature. As it comes out from the XRPD pattern decomposition, some peaks occur in the crystalline Nano-sponge as well as in the nearly amorphous one, but their areas and, particularly, the intensity versus FWHM (Full Width at Half Maximum) ratio were clearly different, so outlining their different crystallinity. This indicates that a deep decrease occurs in the overall crystal quality as if the crystals transformed into amorphous state. However, this is not the case, since the broadening of the peaks can be reasonably related with an outstanding decrease in crystal size owing to the variation of some crystallization parameters. In fact, as evidenced in fig. 6, the XRPD pattern of the Nano-sponge Para crystalline phase can be generated from the convolution of the XRPD diagram recorded on the Nanosponge crystalline phase. Para-crystalline Nano-sponge showed high loading capacity with nifedipine, it may be supposed due to high cross-linking degree can be found between $\beta$-CD and EC.

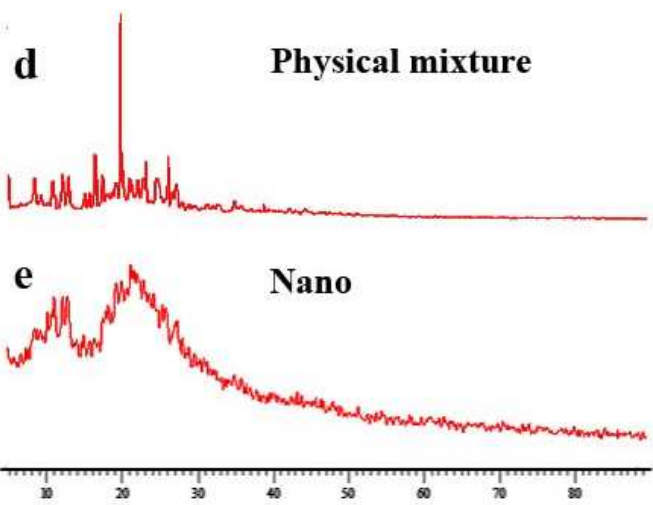

Fig. 6: X ray diagram of a) Nifedipine, (b) EC (Ethyl cellulose), (c) $\beta$ Cyclodextrine, (d) physical mixture, (e) Nano-sponge formula

\section{In vitro drug release}

Fig. (7 a, b and c) showed plots of percent drug released as a function of time for different formulations, respectively. The total amount of drug released for the 1:1 of drug: polymer ratios were
$75.67 \%$ for $\mathrm{F} 1,90.21 \%$ for $\mathrm{F} 4$ and $85.60 \%$ for $\mathrm{F} 7$, observed at different time intervals for a period of $12 \mathrm{~h}$. While the total amount of drug released for the 1:2 of drug: polymer ratios were $65.52 \%$, $75.46 \%$ and $71.43 \%$ for F2, F5 and F8 at $12 \mathrm{~h}$ respectively. At drug: polymer ratios 1: 3 the total amount of drug released at $12 \mathrm{~h}$ were 
$60.66 \%, 65.71 \%$ and $74.32 \%$ for $\mathrm{F} 3, \mathrm{~F} 6$ and $\mathrm{F} 9$ respectively. At $20 \mathrm{~h}$ the total amount of drug released for drug: polymer molar ratios 1: 1 were $90.51 \%, 100 \%$ and $98.87 \%$ for $\mathrm{F} 1, \mathrm{~F} 4$ and $\mathrm{F} 7$ respectively. While the total released were $80.83 \%, 90 \%$ and $88.38 \%$ for F2, F5 and $\mathrm{F} 8$ respectively at drug: polymer molar ratios $1: 2$. The total drug released at drug: polymer molar ratios $1: 3$ were $75.45 \%, 80.61 \%$ and $86.43 \%$ for F3, F6 and F9. It was observed that the release rate was related to drug: polymer ratio. Increase of drug release was observed as a function of drug: polymer ratio. The percent of drug released was decreased with an increase in the amount of polymer for all formulas. This may be due to the fact that the release of drug from the polymer matrix takes place after complete swelling of the polymer and as the amount of polymer in the formulation increased the time required to swell also increased. The release showed a biphasic pattern with an initial burst effect may due to the drug present as non-inclusion complex in the external cavities. In the first-hour drug, the release was found to be ranged of $12 \%$ to $28 \%$. In general, all Nano-sponge formulations showed a prolonged sustained and controlled release up to $24 \mathrm{~h}$ [40]. This release study could be attributed to highest drug loading and optimum degree of cross-linking. It has always been a challenge to control drug release in a predictable manner. Poorly-soluble drugs can be incorporated into Nano-sponge to increase their aqueous solubility by forming inclusion complexes. The poor solubility of Nano-sponge protects the entrapped drug from precipitation and agglomeration by preventing super saturation in the surrounding media. The drug is incorporated in such a way that the hydrophobic functionalities of the drug occupy the hydrophobic interior cavities of cyclodextrin units within the Nano-sponge while the hydrophilic groups present in the drug associate themselves with the hydrophilic external surface which remains exposed to the environment [41]. Judiciously loading active pharmaceutical ingredients into Nano-sponge ensures drug release in a pre-determined manner. Cross-linking Nanosponge provides Nano-cavities into which drugs could be loaded, followed by slow and gradual release. Drug release is dependent on degree of cross-linking and crystallinity. The net effect is enhancement in drug dissolution and consequent increase in drug bioavailability. Employing such systems guarantees optimal drug usage and patient compliance due to less frequency of administration especially in chronic diseases.
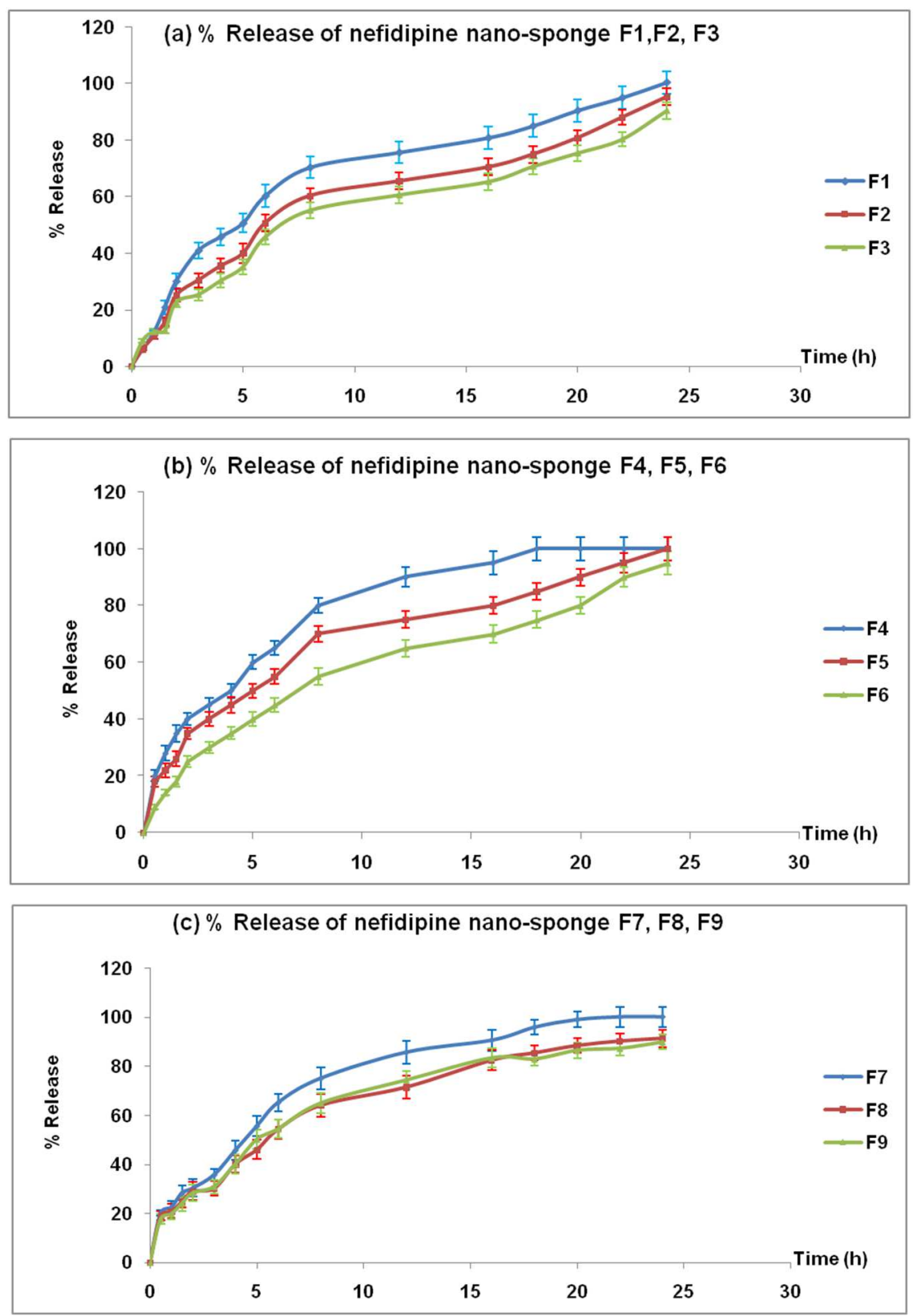

Fig. 7: $(a, b$ and $c) \%$ release of nine formulas of nano-sponge $(M \pm S D)$ 


\section{Kinetic behavior}

The optimized formulation F5 had coefficient of determination $\left(\mathrm{R}^{2}\right)$ values of $0.963,0.932,0.615,0.992,0.98$ and 0.452 for Zero order, First order, second order, Higuchi, Hixon Crowell and n value of Korsmeyer Peppas respectively. A good linearity was observed with the Zero order, the slope of the regression line from Higuchi plot indicates the rate of drug release through the mode of diffusion and to further confirm the diffusion mechanism, data were fitted into the Korsmeyer Peppas equation which showed linearity for optimized formulation. Thus $\mathrm{n}$ value indicates the Fickian diffusion mechanism. Thus, the in vitro release kinetics of the optimized Formula was best fitted to Higuchi model equation which obeyed Fickian controlled diffusion mechanism. Also it was observed that most formulations as F1, F2, F3 and F6 followed the same kinetic release behavior obeyed controlled diffusion as shown in table 5 . In diffusion rate-limited release in addition to drug molecule, diffusion coefficient and length of diffusion path, sometimes effective surface area of drug with release medium are variables during the release process. For a complex system such as there are other factors influencing the release rate among which penetration rate of liquid into the system as hydration, swelling, relaxation, erosion and dissolution of polymer can be mentioned. The extents of liquid penetration and the polymer contributed properties are directly proportional to $t_{1 / 2}$ and powered of $t$, respectively [42].

Table 5: Data fitting for nifedipine release from nano-sponge using the different kinetic model

\begin{tabular}{|c|c|c|c|c|c|c|c|c|}
\hline \multirow[t]{2}{*}{ Formula } & \multirow{2}{*}{$\begin{array}{l}\mathbf{R}^{2} \text { zero } \\
\text { order }\end{array}$} & \multirow{2}{*}{$\begin{array}{l}R^{2} \text { first } \\
\text { order }\end{array}$} & \multirow{2}{*}{$\begin{array}{l}R^{2} \text { second } \\
\text { order }\end{array}$} & \multirow{2}{*}{$\begin{array}{l}R^{2} \\
\text { diffusion }\end{array}$} & \multirow{2}{*}{$\begin{array}{l}\mathbf{R}^{2} \text { hixon } \\
\text { crowell }\end{array}$} & \multirow{2}{*}{$\begin{array}{l}R^{2} \text { baker and } \\
\text { lonsdal }\end{array}$} & \multicolumn{2}{|c|}{ Korsmeyer-peppas model } \\
\hline & & & & & & & n & Model \\
\hline F1 & 0.93465 & -0.93937 & 0.619651 & 0.980937 & 0.978862 & 0.979416 & 0.64906814 & Non Fickian diffusion \\
\hline F2 & 0.96063 & -0.95272 & 0.747903 & 0.990052 & 0.976991 & 0.959776 & 0.66319326 & Non-Fickian diffusion \\
\hline F3 & 0.97011 & -0.96779 & 0.834629 & 0.991079 & 0.981021 & 0.962395 & 0.60702618 & Non Fickian diffusion \\
\hline F4 & 0.93192 & -0.99722 & 0.877475 & 0.979332 & 0.991327 & 0.992458 & 0.42260813 & Fickian diffusion \\
\hline F5 & 0.96315 & -0.9327 & 0.615216 & 0.992797 & 0.981424 & 0.976247 & 0.45241417 & Fickian diffusion \\
\hline F6 & 0.97801 & -0.95569 & 0.773501 & 0.996163 & 0.982102 & 0.958582 & 0.58541112 & Fickian diffusion \\
\hline F7 & 0.94432 & -0.98259 & 0.850637 & 0.983286 & 0.9931 & 0.993772 & 0.46966562 & Fickian diffusion \\
\hline F8 & 0.96548 & -0.99840 & 0.971899 & 0.992114 & 0.993449 & 0.997399 & 0.46219493 & Fickian diffusion \\
\hline F9 & 0.95151 & -0.99395 & 0.985519 & 0.987181 & 0.984553 & 0.994819 & 0.47167783 & Fickian diffusion \\
\hline
\end{tabular}

$\mathrm{n}$ is the diffusional release exponent indicative of the operating release mechanism

\section{In vivo drug absorption study}

This study aimed to define the pharmacokinetics of nifedipine following oral administration of a new extended-release formulation F5 and conventional marketed formula after a single oral dose of 20 mg nifedipine of each. Non compartmental pharmacokinetic parameters were then calculated. The corresponding mean \pm SD of pharmacokinetic parameters are listed in table 6. Plasma concentration-time curves of nifedipine after $20 \mathrm{mg}$ single oral dose of the conventional and the slow release forms are shown in fig. 8 . The results of one way ANOVA statistical analysis are clarified in table 7 . The maximum plasma nifedipine concentration $\left(\mathrm{C}_{\max }\right)$ achieved by $20 \mathrm{mg}$ of the slow release formula (F5) was significantly higher than that achieved by the same dose of the conventional formula $\left({ }^{* * *} \mathrm{p}<0.001\right)$. There is no significant difference in time for maximum drug concentration $\left(\mathrm{T}_{\max }\right)$. The absorption rate constant $\left(\mathrm{k}_{\mathrm{ab}}\right)$ of the conventional form was significantly higher than that of F5 $\left({ }^{* * *} \mathrm{p}<0.001\right)$, consequently the absorption half-life $\left(\mathrm{T}_{1 / 2 \mathrm{ab}}\right)$ was also higher $\left({ }^{* * *} \mathrm{p}<0.001\right)$. The elimination rate constant $\left(\mathrm{k}_{\mathrm{e} 1}\right)$ of the slow release form tends to be lower than that of the conventional form $\left({ }^{* * *} \mathrm{p}<0.001\right)$, as a results the elimination half-life $\left(\mathrm{T}_{1 / 2 \mathrm{el}}\right)$ was slower in in F5 $\left({ }^{* *} \mathrm{p}<0.001\right)$. F5 formula showed higher volume of distribution (Vd) $\left({ }^{* * *} \mathrm{p}<0.001\right)$, slower total body clearance $\left({ }^{* *} \mathrm{p}<0.001\right)$, and approximately 3 fold higher in the area under plasma concentration-time curve $\left(\mathrm{AUC}_{0-48}\right)\left({ }^{* * *} \mathrm{p}<0.001\right)$. Also each of area under first moment concentration-time curve (AUMC $0-48$ ) and the mean residence time (MRT) was significantly higher $\left({ }^{* * *} \mathrm{p}<0.001\right)$. The maximum concentration $\left(\mathrm{C}_{\max }\right)$ is shown to reflect not only the rate but also the extent of absorption. $\mathrm{C}_{\max }$ is highly correlated with the area under the curve (AUC), contrasting blood concentration with time. Therefore, use of the $\mathrm{C}_{\max } / \mathrm{AUC}$ ratio is recommended for assessing the equivalence absorption rates is independent of both intra-subject variation and possible differences in the extent of absorption and reflects only the contrast between the absorption and disposition rate constants $(\mathrm{ka} / \mathrm{k})$ [43]. The ratio was significantly higher in conventional form $\left({ }^{* * *} \mathrm{p}<0.001\right)$ reflecting faster absorption rate. Comparing the pharmacokinetic parameters pointed to that nifedipine loaded Nano-sponge formula can be taken with reducing dose and/or frequency and as consequence side effect with increasing bioavailability.

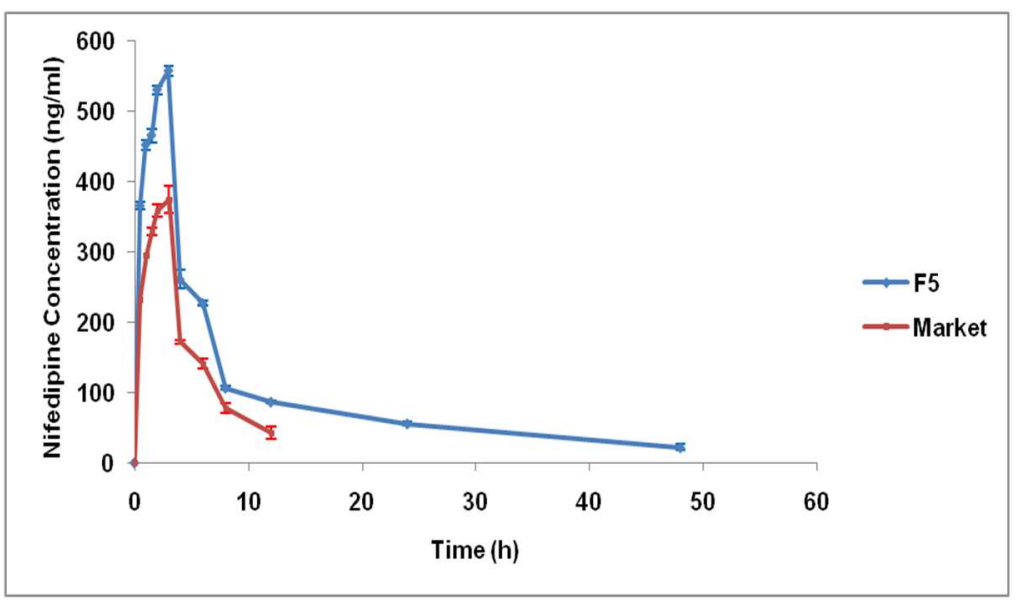

Fig. 8: Mean $\pm S D$ plasma concentration profile for six albino rabbits obtained after oral administration of 20 mg nifedipine of optimum formula F5 and marketed nifedipine 
Table 6: Mean \pm SD of pharmacokinetic parameters of marketed formula and F5

\begin{tabular}{|c|c|c|}
\hline Parameters & Marketed formula & F5 \\
\hline $\mathrm{T}_{\max }(\mathrm{h})$ & 3 & 3 \\
\hline $\mathrm{C}_{\max }(\mathrm{ng} / \mathrm{ml})$ & $0.374 \pm 0.006$ & $0.557 \pm 0.006$ \\
\hline $\mathrm{K}_{\mathrm{ab}}\left(\mathrm{h}^{-1}\right)$ & $0.975 \pm 0.072$ & $0.298 \pm 0.044$ \\
\hline $\mathrm{T}_{1 / 2 \mathrm{ab}}(\mathrm{h})$ & $0.712 \pm 0.050$ & $2.357 \pm 0.370$ \\
\hline $\mathrm{K}_{\mathrm{el}}\left(\mathrm{h}^{-1}\right)$ & $0.287 \pm 0.011$ & $0.081 \pm 0.003$ \\
\hline $\mathrm{T}_{1 / 2 \mathrm{el}}(\mathrm{h})$ & $2.416 \pm 0.092$ & $8.552 \pm 0.408$ \\
\hline $\operatorname{Vd}(\mathrm{L})$ & $30.672 \pm 0.942$ & $50.501 \pm 3.526$ \\
\hline $\mathrm{T}_{\mathrm{cl}}(\mathrm{ml} / \mathrm{min})$ & $146.669 \pm 4.296$ & $68.384 \pm 7.149$ \\
\hline $\mathrm{AUC}_{0-48}(\mathrm{ng} . \mathrm{h} / \mathrm{ml})$ & $1.887 \pm 0.062$ & $4.615 \pm 0.107$ \\
\hline $\mathrm{AUC}_{48-\infty}(\mathrm{ng} . \mathrm{h} / \mathrm{ml})$ & $0.148 \pm 0.033$ & $0.267 \pm 0.067$ \\
\hline $\operatorname{AUC}_{0-\infty}(\mathrm{ng} . \mathrm{h} / \mathrm{ml})$ & $2.035 \pm 0.085$ & $4.882 \pm 0.174$ \\
\hline $\mathrm{AUMC}_{0-48}\left(\mathrm{ng} . \mathrm{h}^{2} / \mathrm{ml}\right)$ & $7.786 \pm 0.338$ & $54.542 \pm 3.668$ \\
\hline $\operatorname{AUMC}_{48-\infty}\left(\mathrm{ng} \cdot \mathrm{h}^{2} / \mathrm{ml}\right)$ & $1.784 \pm 0.398$ & $12.839 \pm 3.221$ \\
\hline $\operatorname{AUMC}_{0-\infty}\left(\mathrm{ng} \cdot \mathrm{h}^{2} / \mathrm{ml}\right)$ & $9.571 \pm 0.688$ & $67.381 \pm 6.867$ \\
\hline MRT(h) & $4.697 \pm 0.163$ & $13.779 \pm 0.901$ \\
\hline $\mathrm{C}_{\max } / \mathrm{AUC}_{0-48}\left(\mathrm{~h}^{-1}\right)$ & $0.198 \pm 0.004$ & $0.120 \pm 0.002$ \\
\hline
\end{tabular}

Table 7: One way ANOVA statistical analysis of pharmacokinetic parameters

\begin{tabular}{|c|c|c|c|}
\hline Parameters & Mean difference & $\mathbf{q}$ & P value \\
\hline $\mathrm{C}_{\max }(\mathrm{ng} / \mathrm{ml})$ & -0.1830 & 52.828 & $* * * \mathrm{p}<0.001$ \\
\hline $\mathrm{K}_{\mathrm{ab}}\left(\mathrm{h}^{-1}\right)$ & 0.6770 & 18.310 & $* * * \mathrm{p}<0.001$ \\
\hline $\mathrm{T}_{1 / 2 \mathrm{ab}}(\mathrm{h})$ & -1.645 & 13.101 & $* * * p<0.001$ \\
\hline $\mathrm{Kel}_{\mathrm{el}}\left(\mathrm{h}^{-1}\right)$ & 0.2060 & 39.008 & $* * * \mathrm{p}<0.001$ \\
\hline $\mathrm{T}_{1 / 2 \mathrm{el}}(\mathrm{h})$ & -6.136 & 42.985 & $* * * \mathrm{p}<0.001$ \\
\hline $\operatorname{Vd}(\mathrm{L})$ & -19.829 & 15.782 & $* * * \mathrm{p}<0.001$ \\
\hline $\mathrm{T}_{\mathrm{cl}}(\mathrm{ml} / \mathrm{min})$ & -3.251 & 45.812 & $* * * \mathrm{p}<0.001$ \\
\hline $\mathrm{AUC}_{0-48}(\mathrm{ng} . \mathrm{h} / \mathrm{ml})$ & -2.728 & 59.160 & $* * * \mathrm{p}<0.001$ \\
\hline $\mathrm{AUC}_{48-\infty}$ (ng. h/ml) & -0.119 & 4.372 & $* \mathrm{p}<0.05$ \\
\hline $\mathrm{AUC}_{0-\infty}$ (ng. h/ml) & -2.847 & 40.386 & $* * * \mathrm{p}<0.001$ \\
\hline $\mathrm{AUMC}_{0-48}\left(\mathrm{ng} \cdot \mathrm{h}^{2} / \mathrm{ml}\right)$ & -37.756 & 30.621 & $* * * \mathrm{p}<0.001$ \\
\hline $\operatorname{AUMC}_{48-\infty}\left(\mathrm{g} \cdot \mathrm{h}^{2} / \mathrm{ml}\right)$ & -11.055 & 10.143 & $* * * \mathrm{p}<0.001$ \\
\hline $\operatorname{AUMC}_{0-\infty}\left(\mathrm{ng} . \mathrm{h}^{2} / \mathrm{ml}\right)$ & -57.810 & 25.006 & $* * * \mathrm{p}<0.001$ \\
\hline MRT(h) & -9.082 & 29.296 & $* * * \mathrm{p}<0.001$ \\
\hline $\mathrm{C}_{\max } / \mathrm{AUC}_{0-48}\left(\mathrm{~h}^{-1}\right)$ & 0.078 & 39.000 & $* * * \mathrm{p}<0.001$ \\
\hline
\end{tabular}

$\mathrm{q}=$ studentized range distribution, $\mathrm{p}=$ probability

\section{In vitro cytotoxicity}

Numbers of cultured cells used in the experiment were 100,000 cell of each kidney (Vero) and liver (HepG2). MTT assay measures the cell metabolic activity, which is directly proportional to cell numbers [44]. The percentages of viable cells were determined in relation to the control cells fig. $(9 \mathrm{~A}, \mathrm{~B})$ and fig. $(10 \mathrm{~A}, \mathrm{~B})$. Cytotoxic effects of Nanosponge loaded drug on Vero and HepG2 cells proliferation, viability and IC50 were carried out by MTT cytotoxicity assay as shown in tables 8 and 9. Different diluted concentrations of the tested Nanosponge sample on cells viability were carried out starting from 1000 $\mu \mathrm{g} / \mathrm{ml}$ to $19.531 \mu \mathrm{g} / \mathrm{ml}$. At high concentrations, toxicity was clear by cycling and shrinkage of both Vero and HepG2 cells. For epithelial kidney cells at $1000 \mu \mathrm{g} / \mathrm{ml}$ concentration viability\% was low $(6.957 \%)$ and toxicity $\%$ was high (93.042\%). For epithelial liver cells viability $\%$ was $(11.024 \%)$ and toxicity $\%$ was $(88.975 \%)$. With dilution, the viability $\%$ increased while the toxicity $\%$ decreased hence at concentration $39.06 \mu \mathrm{g} / \mathrm{ml}$ the viability\% of Vero cells was $(99.169 \%)$, the toxicity $\%$ was $(0.830 \%)$. At concentration $19.531 \mu \mathrm{g} / \mathrm{ml}$ the viability\% of HepG2 cells was (99.392\%), toxicity\% was $(0.607 \%)$. Decrease in cell growth measured by IC50 was $107.754 \mu \mathrm{g} / \mathrm{ml}$ for Vero cells while IC50 for HepG2 cells was $147.736 \mu \mathrm{g} / \mathrm{ml}$. Due to small size of Nano-sponge and high cellular uptakes the toxicity was great at high concentration and decreased with dilution. Toxicity test with all previous tests proved high efficient Nano-sponge loaded drug in addition to safety increased with decreased concentration. Also relation the numbers of tested cells to the numbers of whole boy cells (average $70 \mathrm{Kg}$ body weight) the toxicity decline, so it concludes that nifedipine loaded Nano-sponge safe to administer orally at low concentration.

Table 8: Cytotoxic effects of the nano-sponge loaded drug on vero cells

\begin{tabular}{|c|c|c|c|c|c|c|c|c|c|}
\hline ID & Conc. ug/ml & O. D. & & & Mean O. D. & ST. E & Viability \% & Toxicity \% & IC50 \\
\hline \multirow[t]{2}{*}{ vero } & $1: 2$ & 0.325 & 0.323 & 0.315 & 0.321 & 0.003055 & 100 & 0 & $\mathrm{ug} / \mathrm{ml}$ \\
\hline & 10000 & 0.02 & 0.026 & 0.021 & 0.022333 & 0.001856 & 6.957424714 & 93.04257529 & \\
\hline \multirow[t]{9}{*}{1} & 5000 & 0.024 & 0.023 & 0.021 & 0.022667 & 0.000882 & 7.061266874 & 92.93873313 & 107.754 \\
\hline & 2500 & 0.025 & 0.025 & 0.024 & 0.024667 & 0.000333 & 7.684319834 & 92.31568017 & \\
\hline & 1250 & 0.026 & 0.031 & 0.032 & 0.029667 & 0.001856 & 9.241952233 & 90.75804777 & \\
\hline & 625 & 0.035 & 0.04 & 0.029 & 0.034667 & 0.00318 & 10.79958463 & 89.20041537 & \\
\hline & 312.5 & 0.056 & 0.067 & 0.082 & 0.068333 & 0.007535 & 21.28764278 & 78.71235722 & \\
\hline & 156.25 & 0.072 & 0.088 & 0.094 & 0.084667 & 0.006566 & 26.37590862 & 73.62409138 & \\
\hline & 78.125 & 0.167 & 0.182 & 0.173 & 0.174 & 0.004359 & 54.20560748 & 45.79439252 & \\
\hline & 39.062 & 0.314 & 0.328 & 0.313 & 0.318333 & 0.004842 & 99.16926272 & 0.830737279 & \\
\hline & 19.531 & 0.317 & 0.32 & 0.316 & 0.317667 & 0.001202 & 98.9615784 & 1.038421599 & \\
\hline
\end{tabular}



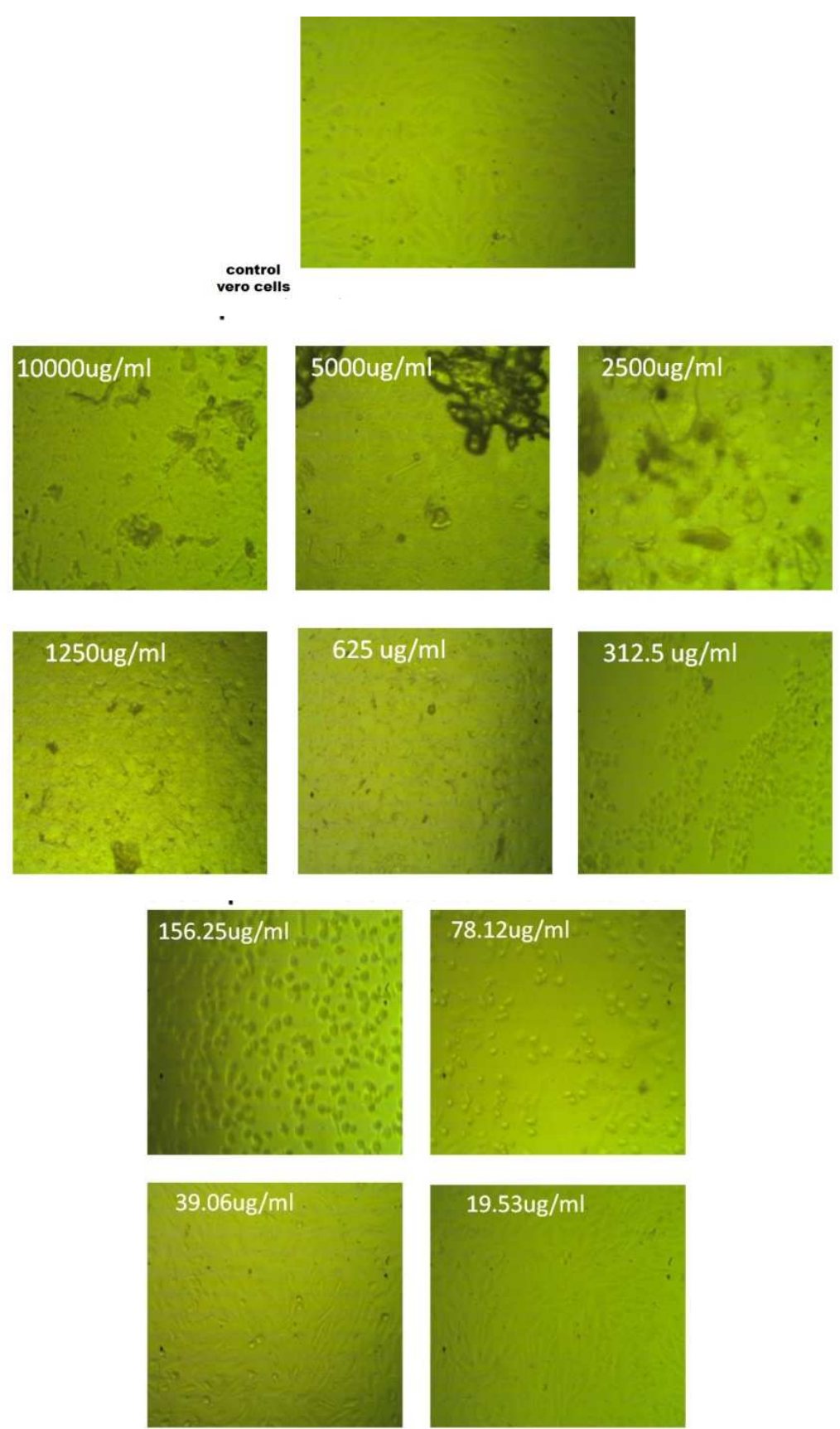

A

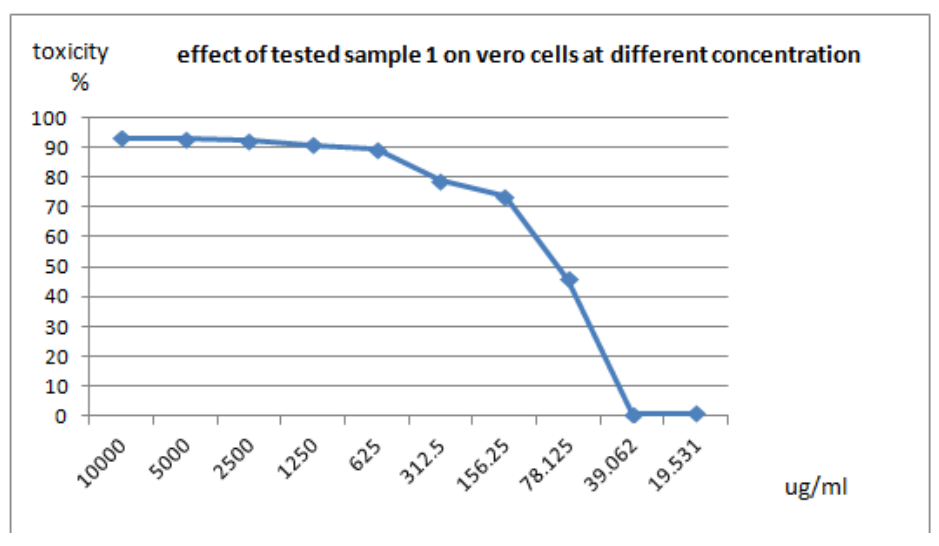

B

Fig. 9: (A and B): Nano-sponge toxicity effect on epithelial kidney cells at different concentrations 

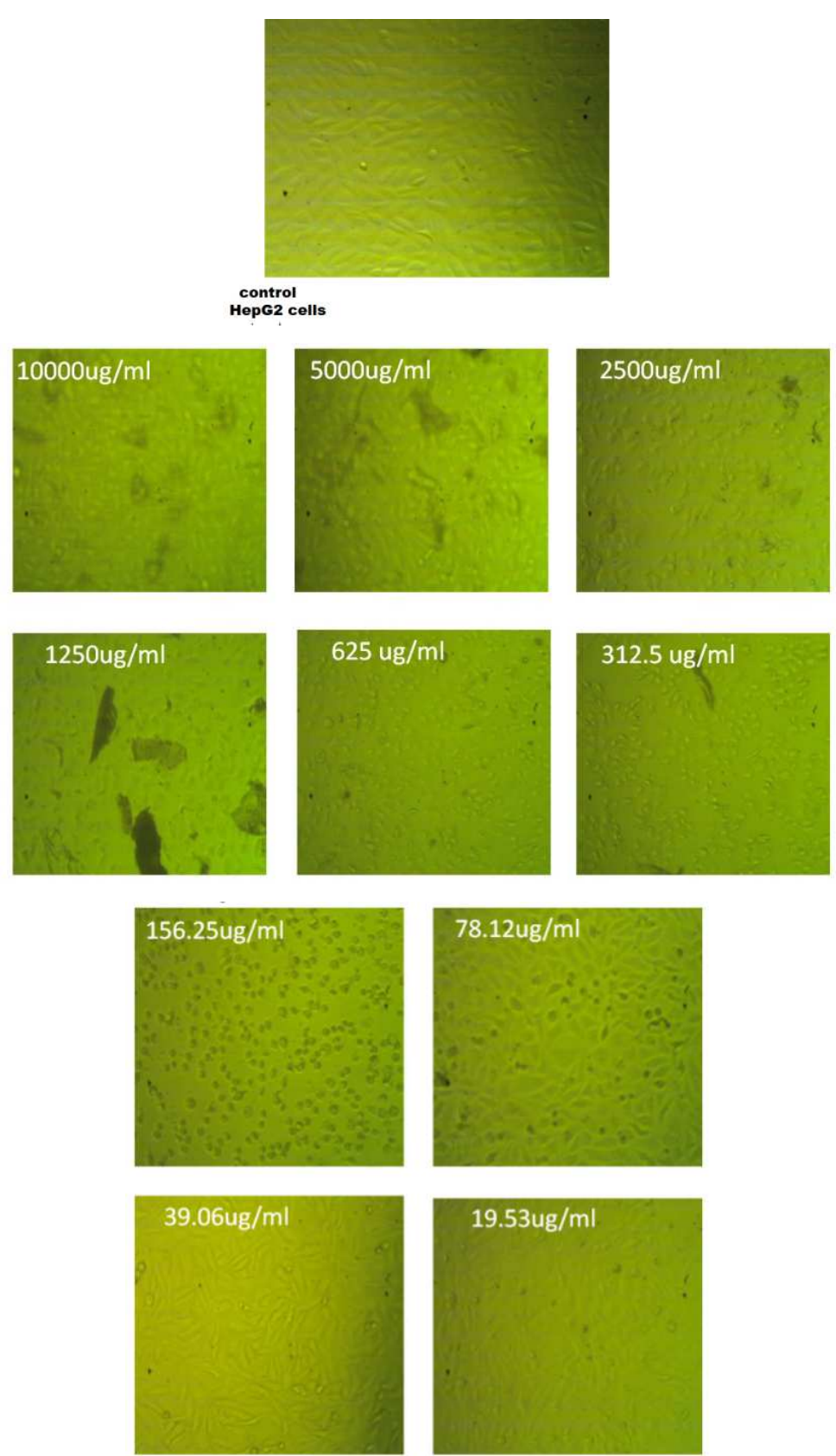

A

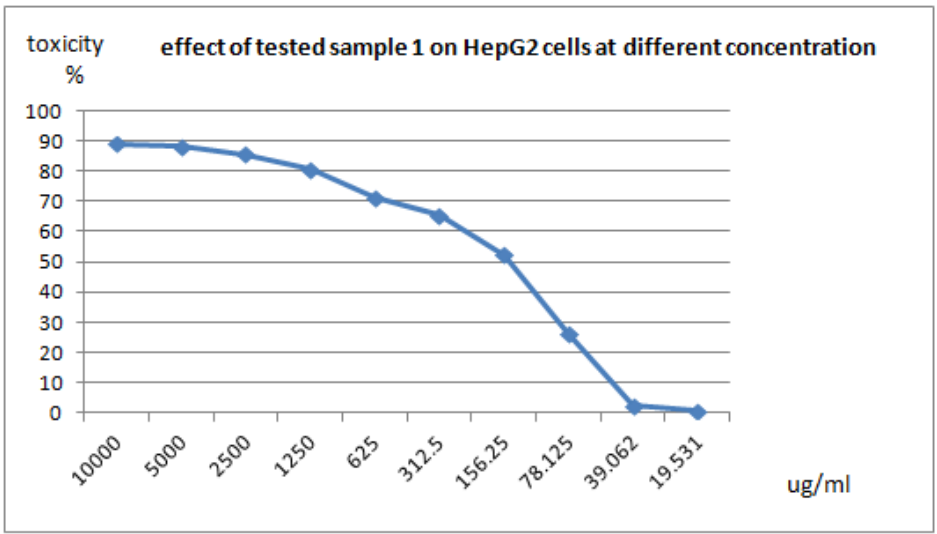

B

Fig. 10 (A and B): Nano-sponge toxicity effect on epithelial liver cells at different concentrations 
Table 9: Cytotoxic effects of nano-sponge loaded drug on HepG2 cells

\begin{tabular}{|c|c|c|c|c|c|c|c|c|c|}
\hline ID & Conc. ug/ml & O. D. & & & Mean O. D. & ST. E & Viability \% & Toxicity \% & IC50 \\
\hline \multirow[t]{2}{*}{ HepG2 } & $1: 2$ & 0.386 & 0.394 & 0.372 & 0.384 & 0.006429 & 100 & 0 & $\mathrm{ug} / \mathrm{ml}$ \\
\hline & 10000 & 0.035 & 0.052 & 0.04 & 0.042333 & 0.005044 & 11.02430556 & 88.97569444 & \\
\hline \multirow[t]{9}{*}{1} & 5000 & 0.039 & 0.051 & 0.047 & 0.045667 & 0.003528 & 11.89236111 & 88.10763889 & 147.736 \\
\hline & 2500 & 0.046 & 0.058 & 0.062 & 0.055333 & 0.004807 & 14.40972222 & 85.59027778 & \\
\hline & 1250 & 0.073 & 0.069 & 0.082 & 0.074667 & 0.003844 & 19.44444444 & 80.55555556 & \\
\hline & 625 & 0.106 & 0.117 & 0.108 & 0.110333 & 0.003383 & 28.73263889 & 71.26736111 & \\
\hline & 312.5 & 0.135 & 0.14 & 0.122 & 0.132333 & 0.005364 & 34.46180556 & 65.53819444 & \\
\hline & 156.25 & 0.184 & 0.195 & 0.17 & 0.183 & 0.007234 & 47.65625 & 52.34375 & \\
\hline & 78.125 & 0.286 & 0.294 & 0.27 & 0.283333 & 0.007055 & 73.78472222 & 26.21527778 & \\
\hline & 39.062 & 0.367 & 0.375 & 0.383 & 0.375 & 0.004619 & 97.65625 & 2.34375 & \\
\hline & 19.531 & 0.384 & 0.379 & 0.382 & 0.381667 & 0.001453 & 99.39236111 & 0.607638889 & \\
\hline
\end{tabular}

\section{Hemolytic activity}

For parenteral administration, the non-toxicity of the formulations is essential. To evaluate the safety of the nifedipine-loaded Nano-sponge, hemolytic activity of aqueous drug formula was screened against normal human erythrocytes [45]. Hemolytic activity is expressed in \% hemolysis. It was exhibited low to mild hemolytic effect toward human erythrocytes. Result indicated that drug formula (at dose $5000 \mu \mathrm{g} / \mathrm{ml}$ ) possess minimum hemolytic activity (3.5\%) where (at dose 20,000 $\mu \mathrm{g} / \mathrm{ml}$ ) possess highest hemolytic activity (48.2\%) Hemolytic percentage was found to be increasing with an increase in concentration (table 10). At concentration $1250 \mu \mathrm{g} / \mathrm{ml}$ the amount of hemolysis was negligible $(0.1 \%)$, thereafter Nano-sponge suspensions were non-hemolytic starting at concentration $625 \mu \mathrm{g} / \mathrm{ml}$ to $0.6 \mu \mathrm{g} / \mathrm{ml}$. Nifedipine-loaded formulations also showed good tolerability with erythrocytes; indeed, the amount of hemolysis was negligible, being as much as $99.6-99.7 \%$ of erythrocytes intact after incubation with Nano-sponge optimum formulation. Optical microscopy studies confirmed the intactness of the blood cells after incubation with the Nano-sponge formulation thereby proving its safety (fig. 11, 12). Thus, the formulation might be considered suitable for parenteral administration at dose immediately below $5000 \mu \mathrm{g} / \mathrm{ml}$.

Table 10: In vitro hemolytic activities of nifedipine loaded Nano-sponge

\begin{tabular}{lll}
\hline Nno-sponge drug Conc. $(\boldsymbol{\mu g} / \mathbf{m l})$ & Absorbance $($ at $\mathbf{5 4 0} \mathbf{~ n m})$ & Hemolytic activity \% \\
\hline 20000 & 1.06 & 48.2 \\
10000 & 0.181 & 8.2 \\
5000 & 0.076 & 3.5 \\
1250 & 0.002 & 0.1 \\
625 & 0.001 & 0.0 \\
312.5 & 0.001 & 0.0 \\
156.25 & 0.001 & 0.0 \\
78.125 & 0 & 0.0 \\
39.1 & 0.001 & 0.0 \\
19.5 & 0.001 & 0.0 \\
9.76 & 0 & 0.0 \\
4.88 & 0 & 0.0 \\
2.44 & 0 & 0.0 \\
1.22 & 0 & \\
0.61 & 0 & 0.0 \\
\end{tabular}

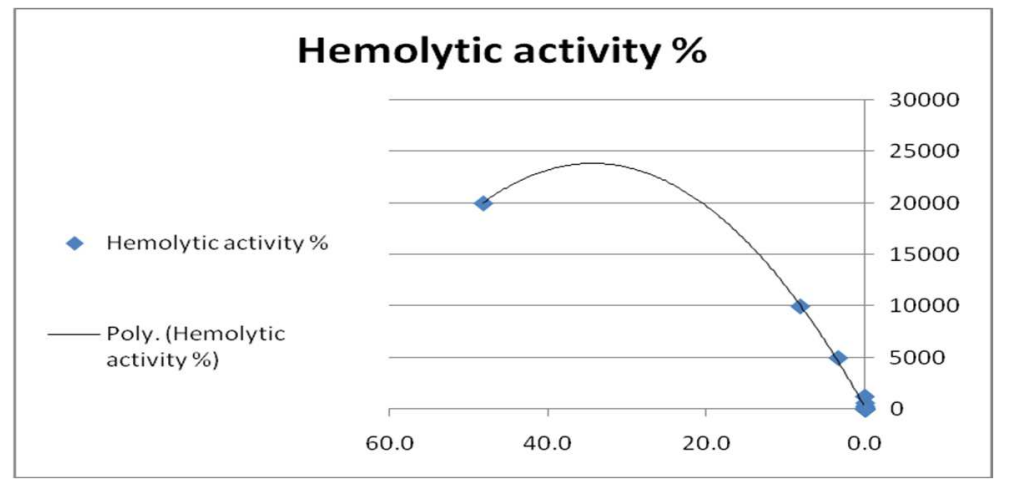

Fig. 11: Hemolytic effect of nano-sponge on human erythrocytes at different concentrations

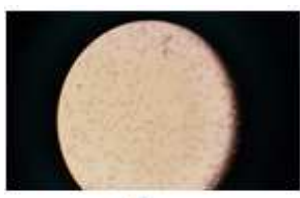

a

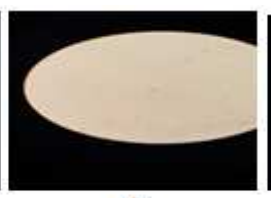

b

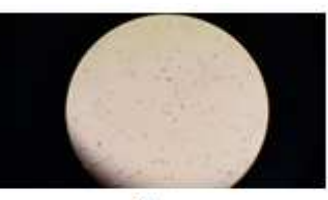

c

Fig. 12: Erythrocyte stability after incubation with Nano-sponge formulation: (a) plain RBC,s, (b) complete hemolysis as control, (c) RBC,s after treatment with concentration $5000 \mu \mathrm{g} / \mathrm{ml}$ 


\section{CONCLUSION}

The Nano-sponge was prepared by the solvent evaporation method. Ingredients used were compatible and the drug was encapsulated in Para crystalline phase. F5 was the optimum formula, its particle size was $181.6 \mathrm{~nm}$; PDI 0.189, percentage entrapment efficiency was $96.63 \%$, drug content $94.75 \%$ and drug released was $75.46 \%$ in $12 \mathrm{~h}$ with sustained pattern. Thermal analysis indicated chemically stability. SEM and TEM photographs revealed the spherical nature of the Nano-sponge in all variations. The release kinetics of optimized formulation was best fitted into Higuchi model and showed zero-order drug release with fickian diffusion mechanism. One way ANOVA statistical analysis of pharmacokinetic parameters for F5 proved significantly higher in all parameters as $\mathrm{C}_{\max }(\mathrm{ng} / \mathrm{ml}), \mathrm{T}_{1 / 2 \mathrm{el}}(\mathrm{h}), \mathrm{Vd}(\mathrm{L}), \mathrm{AUC}_{0-48}(\mathrm{ng} . \mathrm{h} / \mathrm{ml}), \mathrm{AUMC}_{0-\infty}$ (ng. $\mathrm{h}^{2} / \mathrm{ml}$ ) and MRT(h) at ${ }^{* * *} \mathrm{p}<0.001$ compared with conventional marketed formula. In vitro cytotoxicity experiments emphasized safety on both liver and kidney epithelial cells especially at low concentrations in addition to good tolerability with erythrocytes and hemolysis was negligible. Nano-sponge formulation thereby proved its safety and better bioavailability.

\section{ACKNOWLEDGEMENT}

The author is thankful for Epico, Egypt Company for the gift of pure drug, also for Research Lab of Future University in Egypt.

\section{AUTHORS CONTRIBUTIONS}

I designed and executed the research work

\section{CONFLICT OF INTERESTS}

The author has none to declare

\section{REFERENCES}

1. Sharma R, Roderick B, Pathak K. Evaluation of kinetics and mechanism of drug release from Econazole nitrate Nanosponges loaded carbopol Hydrogel. Indian J Pharma Edu Res 2011;45 Suppl 1:25-31.

2. Meena KP, Dang JS, Samal PK, Namedo KP. Recent advances in microsphere manufacturing technology. Int J Pharm Technol 2011;3 Suppl 1:854-5.

3. Trotta F, Cavalli R, Tumiatti W, Zerbinati O, Rogero C, Vallero R. Ultrasound-assisted synthesis of cyclodextrin-based nanosponges. Eur Pharm 2013;1:786-841 B1.

4. Selvamuthukumar S, Anandam S, Kannan K, Manavalan R. Nanosponges. A novel class of drug delivery system-review. J Pharm Pharm Sci 2012;15 Suppl 1:103-11.

5. Rana Z, Gunjan A, Patil P, Zahid Z. Nanosponge-a completely new nano-horizon pharmaceutical applications and recent advances. Drug Dev Ind Pharm PMID 2012;22:585-681.

6. Swarupa A, Irafan K, Sharma JVC. Formulation and in vitro evaluation of $\beta$-cyclodextrin based nanosponges. Scholars Academic J Pharm 2017;6 Suppl 5:175-85.

7. Nacht S, Kantz M. The microsponge: a novel topical programmable delivery system. Top Drug Delivery Systems 2015;42:299-325

8. Kilicarslan M, Baykara T. The effect of the drug/polymer ratio on the properties of verapamil $\mathrm{HCl}$ loaded microspheres. Int J Pharm 2003;252:99-109.

9. Maravajhala V, Papishetty S, Bandlapalli S. Nanotechnology in the development of drug delivery system. Int J Pharm Sci Res 2012;3 Suppl 1:41-9.

10. Ansari K, Torne S, Vavia PR, Trotta F, Cavalli R. Cyclodextrinbased nanosponges for delivery of resveratrol in vitro characterization, stability, cytotoxicity and permeation study. AAPS PharmSciTech 2011;12 Suppl 1:202-10.

11. Hardman JG, Limbird LE, Molinoft PB, Ruddon RW, Gilman AG. In: Goodman, Gilman (Eds.) The Pharmacological Basis of Therapeutics. 9th ed. Mcgraw Hill: New York; 1996. p. 635-6.

12. Miller RJ. Multiple calcium channels and neuronal function. Science 1987;235:46-52.

13. Kleinbloesem $\mathrm{CH}$, Van Brummelen $\mathrm{P}$, Faber $\mathrm{H}$, Danhof $\mathrm{M}$ Vermeulen NPE, Breimer DD. Biochem Pharmacol 1984;33:3721-4.
14. Ohkubo T, Noro H, Sngawara K. Novel drug delivery system nano-sponge as a carrier of an anti-hypertensive drug. J Pharm Biomed Anal 1992;10 Suppl 1:67-75.

15. Rajeswari C, Alka A, Javed A, Khar RK. Cyclodextrins in drug delivery: an update review. AAPS PharmSciTech 2005;6 Suppl 2:E329-57.

16. Ganesh Kumar J, Sreekanth D. Formulation development and evaluation of sustained release matrix tablets of vildagliptinsynthetic and natural polymers. Asian J Pharm 2015;9:2-9.

17. Amidon GE, Mudie DM. Developing solid oral dosage forms. $2^{\text {nd }}$ ed. Science direct; 2017.

18. Raymond C Rowe, Paul J Sheskey, Marian E Quinn. Handbook of pharmaceutical excipients; pharmaceutical press and american pharmacists association; 2009. p. 641-3.

19. Lala R, Thorat A, Gargote C. Current trends in $\beta$-cyclodextrin based drug delivery systems. Int J Res Ayur Pharm 2011;2 Suppl 15:1520-6.

20. Shu XZ, Zhu KJ, Song W. Controlled drug release properties of ionically cross-linked chitosan beads: the influence of anion structure. Int J Pharm 2002;2:217-33.

21. Ghosh T, bharath S, Naik R, Basavaraj BV, Deveswaran R. Formulation and evaluation of buoyant tablets of ketoconazole. Int J Appl Pharm 2019;11 Suppl 2:18-23.

22. Hadjiioannou TP, Christian GD, Koupparis MA, Macheras PE. Quantitative calculations in pharmaceutical practice and research, VCH Publishers Inc, New York; 1993. p. 345-8.

23. Hisham $\mathrm{H}$, Ibrahim AE, Elhenawee M. A novel stabilityindicating HPLC-method for simultaneous determination of atenolol and nifedipine in presence of atenolol pharmacopeial impurities. J Appl Pharm Sci 2015;5 Suppl 8:17-25.

24. Awad Uday Y, Shravan Kumar P, Dinesh Kumar A, Bari Sandip. Estimation of nifedipine by reverse-phase high-performance liquid chromatography tablet dosage form. Int J Pharm Life Sci 2011;2 Suppl 3:610-2.

25. Shah SA, Savale SS, Rathod IS, Shishoo CJ. Development of a sensitive HPLC method for determination of plasma levels of nifedipine. Indian J Pharm Sci 1999;61:81-5.

26. Ahmed M, Ahmed T, Sultan RA, Murtaza G. Pharmacokinetic study of nifedipine in healthy adult male human volunteers. Topical J Pharm Res 2009;8 Suppl 5:385-91.

27. Kang J, Kumar V, Yang D, Chowdhury PR, Hohl RJ. Cyclodextrin complexation: influence on solubility, stability and cytotoxicity of camptothecin. Eur J Pharm Sci 2002;15:163-70.

28. Bulmus V, Woodward M, Lin L, Murthy N, Stayton P, Hoffman A. A new pH-responsive and glutathione-reactive, endosomal membrane-disruptive polymeric carrier for intracellular delivery of biomolecular drugs. J Controlled Release 2003;93:105-20.

29. Jiang J, Oberdo Rster G, Biswas P. Characterization of size, surface charge, and agglomeration state of nanoparticle dispersions for toxicological studies. J Nanopart Res 2009;11 Suppl 1:77-89.

30. Dubes A, Parrot Lopez H, Abdelwahed W, Degobert G, Fessi H, Shahgaldian $\mathrm{P}$, et al. Scanning electron microscopy and atomic force microscopy imaging of solid lipid nanoparticles derivedfrom amphiphilic cyclodextrins. Eur J Pharm Biopharm 2003;55 Suppl 3:279-82.

31. Tansel C, Nursin G, Tamer B. Preparation and in vitro evaluation of modified release ketoprofen microsponges. II Farmaco 2003;58:101-6.

32. Mohammed Manna, Ahmed Abdel Bary, Mona El Assal, Fathy Abdullah. Formulation, optimization, and evaluation of solid dispersions of metformin $\mathrm{HCl}$ using factorial design. Int J Pharm Sci Rev Res 2016;41 Suppl 2:154-60.

33. Gurpreet Kaur, Geeta Aggarwal, Harikumar SL. Nanosponge: new colloidal drug delivery system for topical delivery. Indo Global J Pharm Sci 2015;5 Suppl 1:53-7.

34. Swaminathan S, Vavia PR, Trotta F, Torne S. Formulation of beta-cyclodextrin based nanosponges of itraconazole. J Incl Phenom Macrcycl Chem 2007;57(1 Suppl 4):89-94.

35. Corrigan OI, Healy AM, McDonald BF, Tajber L. Characterisation of excipient-free nanoporous microparticles (NPMPs) of bendroflumethiazide. Eur J Pharm Biopharm 2008;69:1182-6.

36. Barham AS, Corrigan OI, Lorraine MN, McDonald BF, Tajber L. Excipient-free nanoporous microparticles of budesonide for pulmonary delivery. Eur J Pharm Sci 2009;37:593-602. 
37. Swaminathan S, Pastero L, Serpe L, Trotta F, Vavia P, Aquilano $\mathrm{D}$, et al. Cyclodextrin-based nanosponges encapsulating camptothecin: physicochemical characterization, stability and cytotoxicity. Eur J Pharm Biopharm 2010;74:193-201.

38. Suthar V, Pratap A, Raval H. Studies on poly (hydroxy alkanoates)/(ethylcellulose) blends. Bull Mater Sci 2000; 23:215-9.

39. Shanker S, Linda P, Loredana S, Francesco T, Pradeep V, Dino A, et al. Cyclodextrin-based nanosponges encapsulating camptothecin: physicochemical characterization, stability and cytotoxicity. Eur J Pharm Biopharm 2010;74:193-201.

40. Wester R, Patel R, Natch S, Leyden J, Melendres J, Maibach H. Controlled release of benzoyl peroxide from a porous microsphere polymeric system can reduce topical irritancy. J Am Acad Derm 1991;24:720-6.
41. Rana Z, Gunjan P, Zahid Z. Nanosponges-a completely new nano-horizon: pharmaceutical applications and recent advances. Drug Dev Ind Pharm 2012;39:1-10.

42. Macheras P, Dokoumetzidis A. On the heterogeneity of drug dissolution and release. Pharm Res 2000;17:108-12.

43. Endrenyi L, Fritsch S, Yan W. $\mathrm{C}_{\max } / \mathrm{AUC}$ is a clear measure than $\mathrm{C}_{\max }$ for absorption rates in an investigation of bioequivalence. Int J Clin Pharmacol Therapy Toxicol 1991;29 Suppl 10:394-9.

44. Yasmine Y, Caroline Jeba R. In vitro cytotoxicity activity of hydroalcoholic extract of polyherbal churnam (COFRI) in normal liver and kidney cell lines. Asian J Pharm Clin Res 2019;12 Suppl 3:74-7.

45. Prabhakaran D, Rajeshkanna A, Senthamilselvi MM. In vitro antioxidant and anti-inflamatory activity of the flower extract of opuntia stricta. Asian J Pharm Clin Res 2019;12 Suppl 3:208-12. 